\title{
Chronic Sleep Disruption Advances the Temporal Progression of Tauopathy in P301S Mutant Mice
}

\author{
Yan Zhu, Guanxia Zhan, Polina Fenik, Madison Brandes, Patrick Bell, Noelle Francois, Katherine Shulman, \\ and Sigrid Veasey \\ Center for Sleep and Circadian Neurobiology and Department of Medicine, Perelman School of Medicine, University of Pennsylvania, Philadelphia, \\ Pennsylvania 19104
}

Brainstem locus ceruleus neurons ( $\mathrm{LCn}$ ) are among the first neurons across the lifespan to evidence tau pathology, and LCn are implicated in tau propagation throughout the cortices. Yet, events influencing LCn tau are poorly understood. Activated persistently across wakefulness, LCn experience significant metabolic stress in response to chronic short sleep (CSS). Here we explored whether CSS influences LCn tau and the biochemical, neuroanatomical, and/or behavioral progression of tauopathy in male and female P301S mice. CSS in early adult life advanced the temporal progression of neurobehavioral impairments and resulted in a lasting increase in soluble tau oligomers. Intriguingly, CSS resulted in an early increase in AT8 and MC1 tau pathology in the LC. Over time tau pathology, including tangles, was evident in forebrain tau-vulnerable regions. Sustained microglial and astrocytic activation was observed as well. Remarkably, CSS resulted in significant loss of neurons in the two regions examined: the basolateral amygdala and LC. A second, distinct form of chronic sleep disruption, fragmentation of sleep, during early adult life also increased tau deposition and imparted early neurobehavioral impairment. Collectively, the findings demonstrate that early life sleep disruption has important lasting effects on the temporal progression in P301S mice, influencing tau pathology and hastening neurodegeneration, neuroinflammation, and neurobehavioral impairments.

Key words: Gallayas; locus ceruleus; sleep deprivation; tauopathy

\section{Significance Statement}

Chronic short sleep (CSS) is pervasive in modern society. Here, we found that early life CSS influences behavioral, biochemical, and neuroanatomic aspects of the temporal progression of tauopathy in a mouse model of the P301S tau mutation. Specifically, CSS hastened the onset of motor impairment and resulted in a greater loss of neurons in both the locus ceruleus and basolateral/lateral amygdala. Importantly, despite a protracted recovery opportunity after CSS, mice evidenced a sustained increase in pathogenic tau oligomers, and increased pathogenic tau in the locus ceruleus and limbic system nuclei. These findings unveil early life sleep habits as an important determinant in the progression of tauopathy.

\section{Introduction}

Brainstem locus ceruleus neurons ( $\mathrm{LCn}$ ) are sole providers of noradrenaline to the cortices (Foote et al., 1983), and these neu-

\footnotetext{
Received Jan. 26, 2018; revised Aug. 9, 2018; accepted Sept. 15, 2018

Author contributions: G.Z. and S.V. edited the paper; S.V. wrote the first draft of the paper.Y.Z., G.Z.,P.B., and S.V. designed research; Y.Z., G.Z., P.F., M.B., P.B., N.F., and K.S. performed research; S.V. contributed unpublished reagents/analytic tools; Y.Z., G.Z., P.F., M.B., P.B., N.F., K.S., and S.V. analyzed data; Y.Z. and S.V. wrote the paper. This work was supported by National Institutes of Health Grants R01 HL123331, HL 124576, and AG054104 to S.V. The authors declare no competing financial interests.

Correspondence should be addressed to Dr. Sigrid Veasey, University of Pennsylvania, Translational Research Building, 125 South 31st Street, Philadelphia, PA 19104. E-mail: veasey@mail.med.upenn.edu.

https://doi.org/10.1523/JNEUROSCI.0275-18.2018 Copyright (C) 2018 Zhu et al.

This is an open-access article distributed under the terms of the Creative Commons Attribution License Creative Commons Attribution 4.0 International, which permits unrestricted use, distribution and reproduction in any medium provided that the original work is properly attributed.
}

rons help coordinate increased neuronal activity with regional blood flow and glial responses that are critical to optimal cognitive performance and brain health (Aston-Jones et al., 1994; Usher et al., 1999; Strange and Dolan, 2004; Sara, 2009; Bekar et al., 2012). LCn, however, evidence heightened susceptibility in many neurodegenerative processes (Braak et al., 2011). Degeneration of LCn is evident in mild cognitive impairment and early Alzheimer's disease (AD), and the extent of LCn loss predicts cognitive decline (Kelly et al., 2017). LCn seem particularly vulnerable in several tauopathies, including AD. Indeed, somatodendritic tau tangles may be observed in LCn decades before deposition of cortical tangles or clinical AD (Braak et al., 2011). Interestingly, injection of pathogenic tau preformed fibrils into the hippocampus (HC) and other forebrain regions leads to a pronounced concentration of tau aggregates in LCn, relative to 
other brainstem ascending neuronal groups (Iba et al., 2013), and injection of preformed fibrils into the LC results in widespread cortical tau pathology (Iba et al., 2015). In addition to LC vulnerability in tauopathies, injury to the LC can accelerate the temporal progression of pathology in some murine models of $\mathrm{AD}$ and Down's syndrome (Lockrow et al., 2011), whereas lesioning LCn in the P301S murine model of tauopathy hastens cognitive decline and gliosis (Chalermpalanupap et al., 2018). Collectively, these findings suggest important feedforward influences between LCn injury and the progression of tauopathy.

Chronic sleep disruption can impart LCn injury and, thus, could influence the progression of tauopathies. Both chronic short sleep (CSS) and chronic fragmentation of sleep (CFS) in young adult mice induce lasting metabolic stress to and degeneration of LCn (Zhang et al., 2014; Zhu et al., 2015, 2016). Intriguingly, neuronal activation increases brain tau, tau pathology, and even propagation of tau via exosomes (Yamada et al., 2014; Wu et al., 2016; Wang et al., 2017). LCn demonstrate sustained heightened activity across wakefulness (Aston-Jones and Bloom, 1981), which could, therefore, influence LC tau. Importantly, while increased neuronal activity results in a rapid increase in tau (within hours), tau clearance from the interstitial space is protracted (Yamada et al., 2014). We therefore hypothesized that repeated daily exposures to CSS would result in an accumulation of LC tau and potentially induce important pathogenic post-translational modifications of tau, which in a murine model of tauopathy would increase tau pathology and hasten the temporal progression of tauopathy.

While LCn show early involvement in tauopathies, cortical tau likely contributes significantly to both forebrain neurodegeneration and neurobehavioral impairments. We therefore also examined the effects of CSS on tau in tauopathy-vulnerable rostral brain regions and determined whether CFS, as a distinct second form of sleep disruption, influences tau pathology and the temporal progression of behavioral impairment in the murine tauopathy model.

\section{Materials and Methods}

Animals. Studies were performed at the University of Pennsylvania in accordance with the National Institutes of Health Office of Laboratory Animal Welfare Policy and the Institutional Animal Care and Use Committee at the University of Pennsylvania. Male and female mice expressing the human P301S tau mutation (PS19 strain) under regulation of the mouse prion promoter on a mixed C57BL/6NJ (B6) background (B6N.Cg-TgPrnP-MAPT ${ }^{\text {P301S } P S 19 V l e / J) ~ w e r e ~ s t u d i e d, ~ a l o n g ~ w i t h ~ W T ~}$ littermates from hemizygous males and WT females bred in our colony. For each long-term recovery experiment numbers of males and females were equal across sleep conditions. A separate group of no recovery and age-matched rested controls was added, comprised of all males. Tissue from microtubule-associated protein tau knock-out B6.129X1-

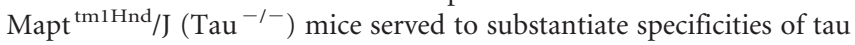
antibodies. Mice were housed in a light/dark environment with lights on from 7:00 A.M. to 7:00 P.M. and fed ad libitum standard rodent chow and water throughout experimentation.

Chronic sleep disruption. Two distinct forms of sleep disruption were examined: CSS and CFS. CSS was achieved using a continuously monitored enriched environment in which novel climbing toys were periodically exchanged whenever a mouse became behaviorally quiescent (Vankov et al., 1995; Léger et al., 2009; Gompf et al., 2010). A temporal overview of the protocol and general experimental design is presented in Figure $1 A$. On days $1-3$ of each of 4 consecutive weeks, mice were placed along with littermates in the novel environment with standard bedding, chow, and water bottles for the first $8 \mathrm{~h}$ of the lights-on period. Rested controls (Rest) were placed in a similar environment for the first hour of the lights-on period, a time when mice are generally awake. Ambient lighting and temperature were held similar to the home cage environment. Plasma corticosterone levels are not elevated in this chronic paradigm (Zhang et al., 2014). A second approach to chronic sleep disruption, CFS, was implemented to help distinguish tau and behavioral responses to disturbed sleep from responses secondary to an enriched environment and/or increased locomotor activity, present only in the CSS paradigm. Home mouse cages were placed atop a rotor table (rotation speed $1 \mathrm{~Hz} ; 5 \mathrm{~s}$ every minute; $24 \mathrm{~h} / \mathrm{d}$ for 4 weeks). This paradigm increases the arousal frequency from $30 / \mathrm{h}$ to $60 / \mathrm{h}$ without significantly influencing total wake or sleep time in $24 \mathrm{~h}$ (Zhu et al., 2015).

Neurobehavioral testing. Motor and memory impairments, hyperactivity, and disinhibition have been identified early in P301S mice (Yoshiyama et al., 2007; Dumont et al., 2011; Takeuchi et al., 2011; Przybyla et al., 2016). The hindlimb retraction assay and ledge walk assessment tests were performed as previously described (Guyenet et al., 2010) on CSS and Rest mice 1 and 3 months after CSS (ages 5 and 7 months). Mice were habituated to handlers for $3 \mathrm{~d}$ before testing. Tests were scored on an integer scale $0-3$, with 0 as normal performance and 3 as continuous clasping of hind limbs (limb retraction assay) or inability to move forward along the ledge (Guyenet et al., 2010). Each of these tests was repeated 4 times and an average score was used for the time point.

A second group of mice Rest and CSS P301S mice was assessed for open field activity, novel and spatial object recognition memory at 7 months (4 months after CSS or Rest conditions). Locomotor activity (distance traveled/min in open field) and percentage of time in center 10 $\mathrm{cm} \times 10 \mathrm{~cm}$ were quantified, in an open field, measuring $50 \times 50 \mathrm{~cm}^{2}$, and illuminated from above by 25 lux. Mice were placed individually into the arena and monitored for $10 \mathrm{~min}$ by a video camera (Sony CCD IRIS). Transitory data were analyzed with tracking using the image processing system EthoVision 3.1 (Noldus Information Technology). The novel and spatial object memory protocols were adapted from detailed published protocols (Sinha et al., 1999; Youmans et al., 2011). Mice were habituated to a $60 \mathrm{~cm} \times 50 \mathrm{~cm} \times 30 \mathrm{~cm}$ chamber without objects for $5 \mathrm{~min}$ for three consecutive mornings with lighting as above. The spatial object test was run 1 week and the novel object test the following week. For the spatial object test, on test day, mice received two $5 \mathrm{~min}$ training sessions, $30 \mathrm{~min}$ apart, followed by the test $3 \mathrm{~h}$ later in which one of two objects was moved. Between training and testing sessions, mice were left unperturbed in home cages. The only difference in the novel object test was that, during the test phase, one object was randomly replaced with a novel object. Scorers reviewing videos were blinded to the conditions and genotypes of mice. The percentage of time spent attending the original object relative to time spent attending the moved or novel object was determined for each mouse for both trial and test conditions.

Antibodies. Primary antibodies used for characterization of immunoblot and immunohistochemistry responses were as follows: AT8 Tau (PSer202, Thr 205; MN1020, Thermo Fisher Scientific); P202 Tau (Pser202; 11834, Cell Signaling Technology); AT180 Tau (PThr231; MN1040, Thermo Fisher Scientific); MC1 Tau (kind gift from Peter Davies); TOMA-1 (oligomeric tau, MABN819, Millipore), Tau-5 (total tau; Ab80579, Abcam); CD68 (Ab125212, Abcam); ionized calcium binding adapter protein 1, Iba-1 (Ab107159, Abcam); GFAP (Ab7260, Abcam); and TH (LS-C124752, LSBio, and 22941, Immunostar).

Immunoblotting. Mice designated for protein lysate assays were decapitated, and brains were frozen on dry ice, sectioned coronally $0.3-$ to 0.5 -mm-thick on a cooling block, and then, using an \#11 gauge scalpel and dissecting scope, LC and EC tissue was immediately excised and homogenized on ice in TBS lysis buffer with protease inhibitor mixture (P8340, Sigma), phosphatase inhibitor (Halt, 1862495, Thermo Fisher Scientific), and $1 \%$ Triton to improve capture of all tau (Sahara et al., 2002). LC-enriched samples were taken to include much of the LC nucleus and dendritic field but likely included some of the lateral dorsal tegmentum and mesencephalic trigeminal neurons, whereas ECenriched samples may have included some of the external capsule. Protein extracts (20 $\mu \mathrm{g} / \mathrm{sample}$, BCA measured) were run on SDS-PAGE and transferred to nitrocellulose membranes. Loading buffer (TBS 92750000 , Odyssey) was used to enhance phosphorylated target protein signal. $\beta$-Mercaptoethanol and DTT were removed from loading buffer to capture oxidized tau oligomers (Kim et al., 2015). Gels were imaged and 
A

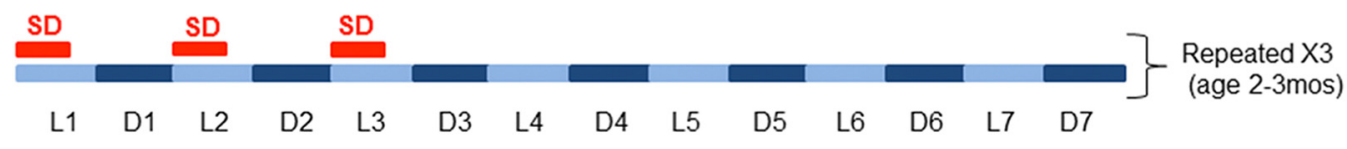

B

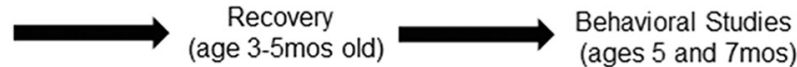

C

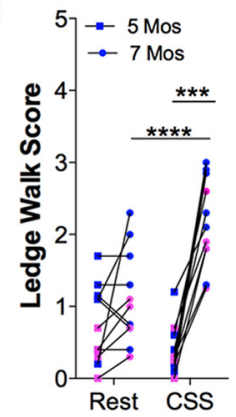

G

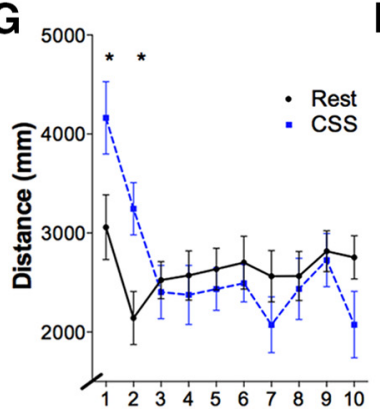

D

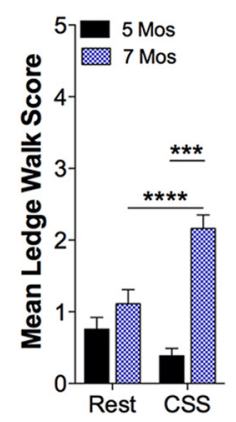

H

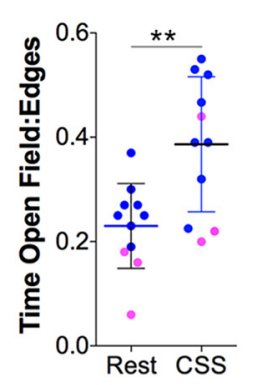

$\mathbf{E}$

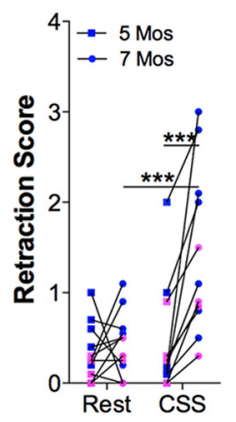

I

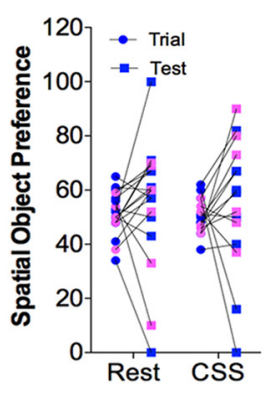

Biochemical or Histology Studies (age 9-10mos)

Figure 1. Temporal overview of study design and effects of CSS on neurobehavioral performance in P301S mutant mice. $A$, Schematic of the CSS paradigm, where total sleep deprivation (SD, red bars) occurred at the onset of the first three lights-on (light blue) periods of the week (L1, L2, and L3) for 8 consecutive hours. Mice were returned to home cages for the last $4 \mathrm{~h}$ of the $L 1, L 2$, and $L 3$ periods and the ensuing lights off (dark blue bars, D1, D2, and D3) periods. Mice were left undisturbed in home cages for days $4-7$ each week. The pattern was repeated weekly for 4 consecutive weeks. $\boldsymbol{B}$, Following CSS and Rest control conditions, mice recovered 3 months before behavioral tests at ages 5 and 7 months and then an additional $2-3$ months before undergoing the specified protein assays at ages $9-10$ months. $C, D$, Individual and group (mean \pm SE) scores for the ledge walk test, where higher scores, to a maximum of 3 , indicate greater impairment $(n=11: 7$ male, 4 female/group). Individual data points: blue represents male; pink represents female. $\boldsymbol{E}, \boldsymbol{F}$, Individual (same color scheme/gender) and group scores for hindlimb retraction, where scores to a maximum of 3 indicate impairment ( $n=11: 7$ male, 4 female/group). G, Locomotor distance (mm) per minute in novel environment (mean \pm SE) for 10 min in Rest (black) and CSS (blue) mice. $n=11$ ( 8 male, 3 female/group). $\boldsymbol{H}$, Individual data points (blue represents male; pink represents female) for ratio of time spent in center of open field relative to edges (also $n=11: 8$ male, 3 female/group). Error bars indicate mean \pm SE. I, Spatial object memory response expressed as percentage preference to moved object. $n=11$ ( 8 male, 3 female/group). Individual data points, coded as above, with paired responses for before move (trial, circle) and after move (test, square). J, Novel object memory test with paired individual data points, coded as above, for preference to original object (trial, circle) and novel object replacement (test, square). $\mathbf{C}-\boldsymbol{F}, \boldsymbol{I}, \boldsymbol{J}$, Repeated-measures ANOVA. G, Two-way ANOVA. $\boldsymbol{H}, \boldsymbol{t}$ test. ${ }^{*} p<0.05,{ }^{* *} p<0.01,{ }^{* * *} p<0.001,{ }^{* * * *} p<0.0001$.

analyzed with Odyssey CLx Imager with Odyssey Application software, version 3.0.16 (Li-Cor). Mean integrated densities for $50-80 \mathrm{kDa}$ and $90-160 \mathrm{kDa}$ were normalized to $\alpha$-tubulin, as total tau was altered by CSS.

Histochemistry and stereology. Mice were anesthetized with pentobarbital and transcardially perfused with ice-cold PBS followed by $4 \%$ PFA. Brains were after fixed in PFA and cryopreserved before sectioning as $60-\mu \mathrm{m}$-thick serial coronal slices. Sections were selected (3/region/ mouse) for LC ( -5.20 to -5.80 bregma) (Franklin and Paxinos, 2008), BLA/lateral amygdala $(-1.34$ to -2.15 bregma), rostral $\mathrm{HC}(-1.22$ to -2.54 bregma), and EC ( -3.16 to -4.36 bregma). For light microscopy, free-floating $1 \%$ Triton-treated sections were processed as previously reported (Panossian et al., 2011) using the following titers of tau primary antibodies: AT8 (1:2500) or MC1 (1:500), TH (1:2000), or glial antibodies, Iba-1 (1:1000), CD68 (1:1000), and GFAP (1:500). Enzyme-linked immunohistochemistry was performed with biotinylated secondary antibodies and biotin-avidin peroxidase complex visualized with Vector Blue (Vector Laboratories). Imaging was performed with a DM5500B (Leica Microsystems). Using Fiji (ImageJ) software, images were converted to 8-bit grayscale and thresholded to intense labeling with user blinded to sleep conditions. Percentage area within target region was measured, and target area percentage coverage averages for each mouse were analyzed.

Unbiased optical fractionator stereology for neuronal count estimates, as previously detailed (West and Gundersen, 1990), was performed for LCn and BLA/LA nuclei. LCn were immunolabeled with anti-TH (LSC124752). LCn and amygdala sections were mounted, dried, and counterstained with Giemsa (to identify neurons and nuclei), and sections were confirmed to span the entire rostral-caudal nucleus. A $100 \times$ oil objective was used to count neuronal nuclei in focus within the probe boundaries (DM4B, Leica Microsystems). For LCn, all neurons $\left(\mathrm{TH}^{+}\right.$ and $\mathrm{TH}^{-}$) with soma $>10 \mu \mathrm{m}$ diameter within the confines of the bilateral LC nuclei were counted using a probe size of $50 \mu \mathrm{m} \times 50 \mu \mathrm{m}$ and a counting frame of $100 \mu \mathrm{m} \times 100 \mu \mathrm{m}$ (StereoInvestigator version 11.09, MicroBrightField Biosystems). This strategy, using a 1:2 series of sections provided $>200$ counts, allowed a Gundersen coefficient of error (for $\mathrm{m}=1)<0.09$ in all subjects. Anatomical boundaries of the amygdala subnuclei (lateral and basal amygdala) were delineated as previously described, using fiber tract landmarks and cytologic features of neurons within each group (Chareyron et al., 2011). A 1:3 series was 
examined, unilaterally, using a probe size of $35 \mu \mathrm{m} \times 35 \mu \mathrm{m}$ and a counting frame of $185 \mu \mathrm{m} \times 185 \mu \mathrm{m}$. This allowed counts of $200-450$ neurons per subject and a Gundersen $<0.09$ in all cases.

To identify argyrophilic pathology, including neurofibrillary tangles (NFTs) and neuropil threads, Gallyas silver impregnation was performed on mid LC and BLA/LA ( -5.40 to -5.80 and -1.34 to -2.30 bregma, respectively) $60 \mu \mathrm{m}$ mounted sections ( 2 or $3 /$ region/mouse) as previously detailed (Kuninaka et al., 2015). Timing of developer exposure was optimized to provide absence of signal in WT mice and some strong neuronal labeling in 10-month-old male P301S mice in the amygdala and/or piriform cortices. Sections were imaged using the DM5500B microscope, before and after nuclear fast red counterstain (N8002, SigmaAldrich), and the percentage area of tangles was measured in the above regions, as above for AT8 and MC1 analyses using ImageJ.

Additional sections were analyzed for MC1 and GFAP responses in mice without prolonged recovery after CSS. Sections were processed as above, with the exception that secondary antibodies were conjugated with AlexaFluor probes: 488, 555, or 594 (Invitrogen) for visualization using confocal microscopy (SP5/AOBS, Leica Microsystems). Anti-TH labeling was used to highlight the LC region, and DAPI nuclear labeling was used to delineate hippocampal CA1. Confocal laser intensities, nanometer range, detector gain, exposure time, amplifier offset, and depth of the focal plane within sections per antigen target were standardized across compared sections (Panossian et al., 2011). Percentage area coverage in 2 sections of LC nucleus $(-5.40$ to -5.80 bregma) and the CA1 ( -1.22 to -2.54 bregma) regions was assessed for MC1 and GFAP, using 8-bit grayscale inverted montaged images across $17 \mu \mathrm{m} z$ axis, standardized thresholds with average percentage areas obtained per section/ mouse and analyzed across groups.

Statistical analysis. When a single variable was compared across two groups, the Student's $t$ test (unpaired) was implemented with Bonferroni correction for multiple comparisons; and when three groups were compared, one-way ANOVA with Bonferroni's multiple comparisons test was used. Within-animal memory testing was performed using repeatedmeasures two-way ANOVA with Holm-Sidak multiple-comparison test. Repeated-measures ANOVA was also used to assess changes within animal in neurobehavioral performance over time, using Tukey's multiple-comparison analysis for overall significant interaction(s). For comparisons of $>2$ groups across genotype and sleep conditions, twoway ANOVA was used with Tukey's multiple-comparison post hoc analyses. The cutoff for significant statistical power for all analyses was a multiple-comparisons-corrected $p<0.05$.

\section{Results}

\section{Hastened neurobehavioral deterioration in P301S mice following CSS}

We first determined whether early-life CSS would influence the progression of known neurobehavioral impairments in P301S mice by assessing motor behavior and spatial memory (Yoshiyama et al., 2007; Xu et al., 2014). Motor performance was examined at ages 5 and 7 months ( 1 and 3 months after CSS or Rest conditions), using a ledge walk test and the hindlimb retraction test, both analyzed as $n=11$ ( 7 male, 4 female)/group. The former assesses agility of movement, and the latter is one of the earliest motor deficits observed in P301S mice (Yoshiyama et al., 2007). Overall, there were both age and sleep condition effects on ledge walking ability. Individual and group data are presented in Figure $1 C, D$. In Rest mice, ledge scores were unchanged from 5 to 7 months of age ( $t=1.5$, not significant); whereas in CSS mice, ledge scores deteriorated from 5 to 7 months $(t=4.5, p<0.001)$. Although there was no effect of sleep condition on the ledge test performance at age 5 months ( $t=1.6$, not significant), CSS mice age at 7 months showed poorer performances, relative to agematched Rest mice $(t=8.4, p<0.0001)$. Similarly, there were both age- and sleep-dependent effects on limb retraction, as shown in Figure 1E, F. In Rest mice, hindlimb retraction was unchanged from ages 5 to 7 months ( $t=0.6$, not significant) yet worsened in the CSS group $(t=4.9, p<0.001)$; and as observed with the ledge walk, CSS mice at 7 months evidenced poorer performances than Rest mice at 7 months $(t=3.9, p<0.001)$. A second group of mice was used for locomotor, open field, and memory testing with $n=11$ ( 8 male, 3 female/group). CSSexposed mice showed increased locomotor activity for the first 2 min of the assay $(t=2.9$ and $t=2.9, p<0.05$; Fig. $1 G)$. CSS mice also showed increased relative time in the center:edges in the open field assay $(t=3.4, p<0.01$; Fig. $1 H)$. With spatial memory testing also using an $n=11$ as 8 male, 3 female/group, neither Rest nor CSS mice showed increased place preference for the recently moved object, relative to the unmoved object $(t=0.4$ and $t=0.2$, not significant, respectively; Fig. $1 I$ ). In contrast, only Rest mice showed place preference for a novel object (Rest, $t=$ 6.7, $p<0.0001$; CSS, $t=2.3$, not significant; Fig. $1 J$ ), and CSS mice showed less preference for the novel object relative to Rest mice $(t=5.1, p<0.0001)$. By 8 months, 2 of 11 CSS mice evidenced hunch spines, poor ambulation, and weight loss, whereas no mice within the Rest group evidenced severe motor deficits before 9 months of age. Overall, CSS accelerates deterioration in neurobehavioral performance in P301S mice, whereas short-term spatial memory is already impaired early in the course of disease.

\section{CSS results in a sustained increase in soluble tau, including oligomers}

The LC is one of the first sites with hyperphosphorylated tau, and the EC may be an early site of tau seeding (Braak et al., 2011; Kaufman et al., 2018). Soluble tau oligomers are implicated in both behavioral impairments and neurodegeneration (Santacruz et al., 2005). Nonreducing conditions have unveiled the presence of disulfide oligomeric tau, otherwise obscured in standard reducing gels (Fá et al., 2016). In preliminary studies, we compared reducing and nonreducing conditions for LC MC1 tau and found a robust shift to larger bands, $90-160 \mathrm{kDa}$ under nonreducing conditions, bands that were undetectable in reducing conditions (Fig. 2A). The presence of oligomeric tau in nonreducing conditions was confirmed using an oligomer-specific tau antibody (clone TOMA-1), which also showed a prominent band near 160 $\mathrm{kDa}$, without a signal in the reduced buffer (Fig. 2A). Thereafter, sustained effects of CSS on soluble tau in the LC and EC using nonreducing lysates were examined for monomeric $(50-80 \mathrm{kDa})$ and oligomeric tau $(90-160 \mathrm{kDa})$ in Rest and CSS mice, with $n=$ 9 ( 5 male, 4 female)/group for LC and $n=14$ ( 9 male, 5 female)/ group for EC where protein was more abundant. For all tau antibodies assessed, lysates from $\mathrm{Tau}^{-1-}$ mice showed negligible immunoreactivity between 50 and $160 \mathrm{kDa}$. Representative Rest, CSS, and $\mathrm{Tau}^{-1-}$ images are provided in Figure $2 B, C$. P202 tau $(50-80 \mathrm{kDa})$ was higher in mice exposed to CSS, relative to agematched Rest mice in the LC (Fig. $2 D ; t=2.3, p<0.05)$ and in the EC, relative to Rest mice (Fig. $2 H ; t=3.2, p<0.05$ ). In contrast, AT180 tau $(50-80 \mathrm{kDa})$ was unchanged in the LC (Fig. $2 E ; t=0.6$, not significant) yet increased in EC (Fig. $2 I ; t=2.6$, $p<0.05$ ). CSS increased monomeric LC MC1 tau (Fig. $2 F ; t=$ $3.8, p<0.01$ ) without affecting monomeric EC MC1 tau (Fig. 2J; $t=0.5$, not significant). CSS did not influence monomeric tau5 in either the LC (Fig. 2G; $t=0.2$, not significant) or EC (Fig. $2 K$; $t=0.4$, not significant). We next examined the CSS response to tau oligomers specifically at $90-160 \mathrm{kDa}$ bands. Oligomer bands were not detected for P202 in the LC (Fig. 2B,L). P202 oligomeric band density was evident in the EC and increased in response to CSS (Fig. $2 P ; t=4.2, p<0.001$ ). CSS increased AT180 oligomers in the LC (Fig. $2 M ; t=2.5, p<0.05$ ) and increased AT180 
A

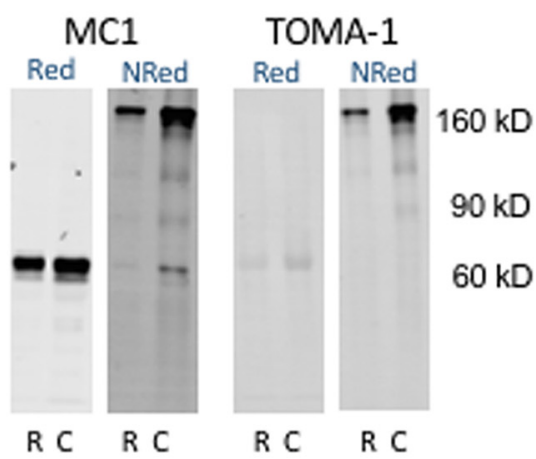

B

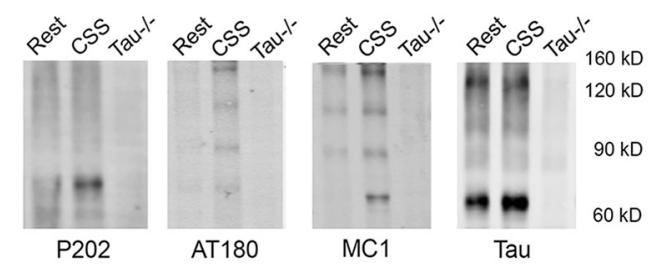

C Entorhinal Cortex

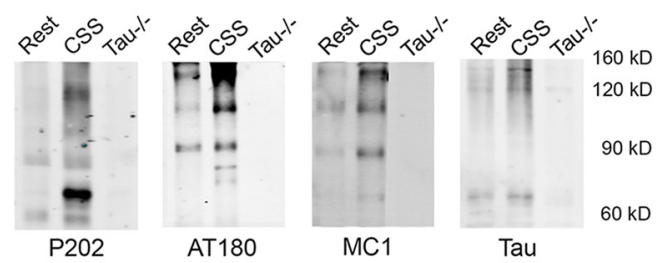

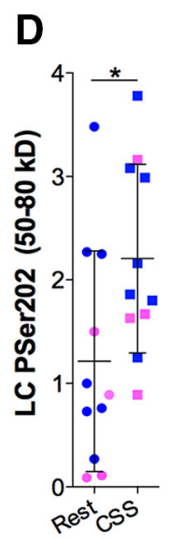

E $\quad F$

G
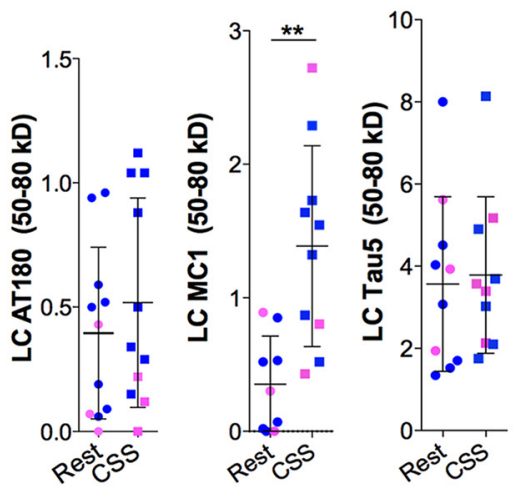

H

J

K

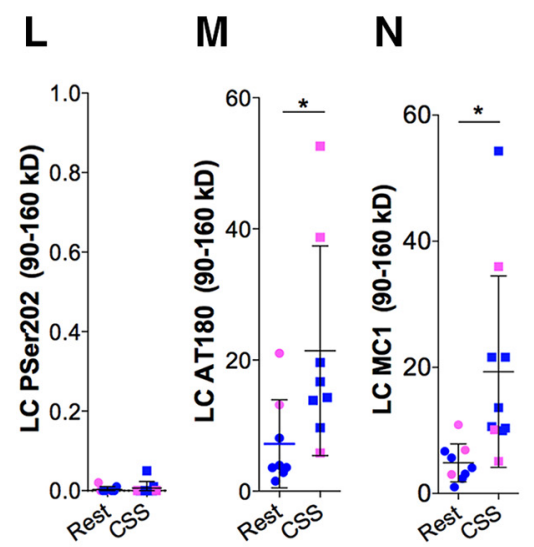

0

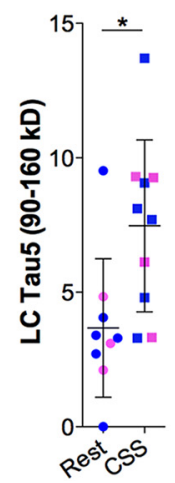

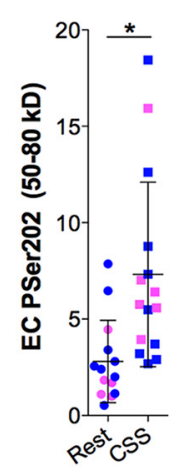
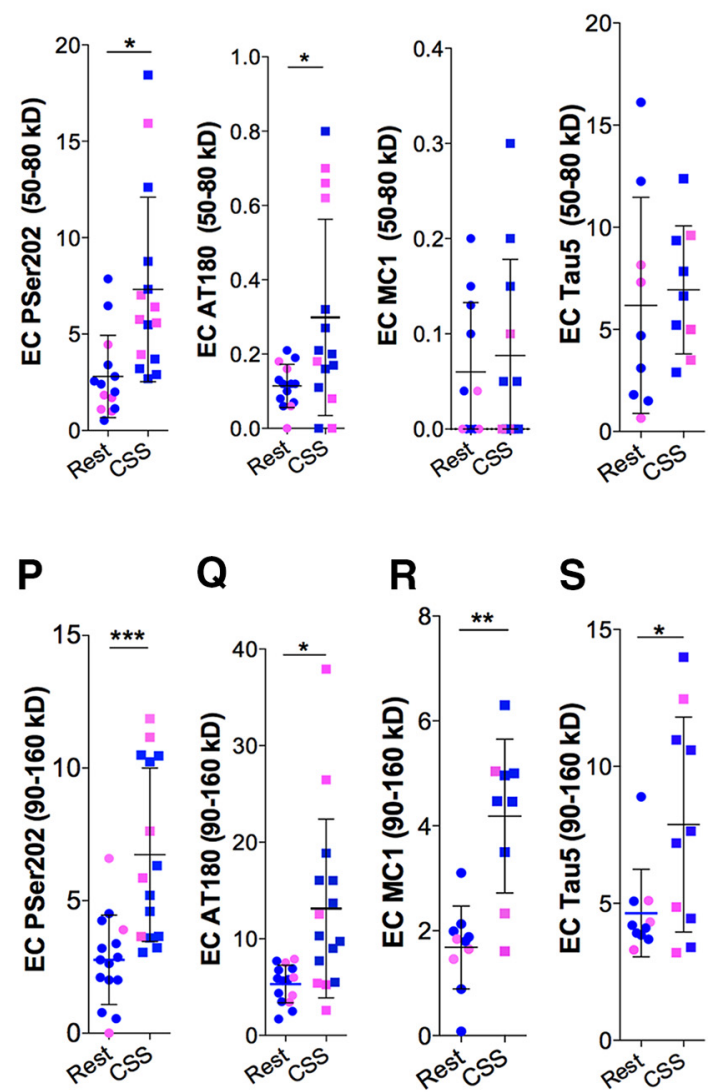

S

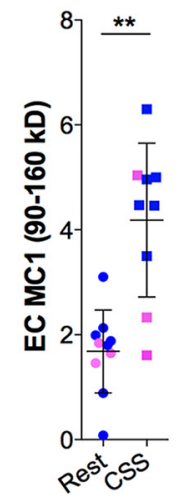

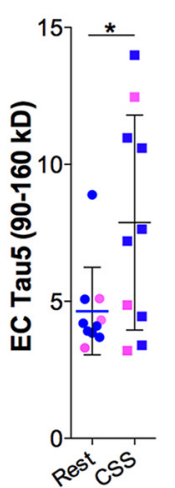

Figure 2. CSS results in lasting increases in soluble tau protein in the $L C$ and EC. $A$, Comparison of MC1 and oligomer (TOMA-1) tau immunoblots from same $L C$ purified protein samples from a Rest P301S mouse (R) and a CSS P301S mouse (C) run under reducing (Red) conditions (left) and nonreducing (NRed) conditions (right). $\boldsymbol{B}$, Representative NRed LC gels (20 $\mu \mathrm{g} /$ lane) from Rest, CSS, and $\mathrm{Tau}^{-1-}$ mice for antibodies to phosphoserine 202 (P202), phosphothreonine 231 (AT180), MC1 tau (MC1), and total tau (Tau5). C, Representative NRed gels from EC in Rest, CSS, and Tau ${ }^{-1-}$ mice for the same antibodies. D-G, Individual normalized immunodensities at 50-80 kDa (monomeric) for LC lysates to P202, AT180, MC1, and Tau5. Individual data points: blue represents male; pink represents female. $n=9$ (5 male, 4 female) for the LC samples. Error bars indicate mean $\pm \mathbf{S E}$. $\boldsymbol{H}-\boldsymbol{K}$, Individual normalized immunodensities at $50-80 \mathrm{kDa}$ for EC for the same antibodies and conditions where $n=14$ (9 male, 5 female) for the EC samples. $L-0$, Individual normalized immunodensities at $90-160 \mathrm{kDa}$ for LC lysates to the same tau antibodies/conditions from the same gels analyzed for monomeric LC. P-S, Individual normalized immunodensities at $90-160 \mathrm{kDa}$ for EC lysates and antibodies, analyzed on gels used for monomeric analysis. Data were analyzed with unpaired $t$ tests. ${ }^{*} p<0.05,{ }^{* *} p<0.01,{ }^{* * *} p<0.001$.

oligomers in the EC (Fig. 2Q; $t=2.8, p<0.05$ ). Similarly, CSS increased $\mathrm{MC1}$ oligomers in both the LC (Fig. $2 N ; t=2.3, p<$ $0.05)$ and the EC (Fig. $2 R ; t=4.7, p<0.001)$. Tau5 oligomers were also increased in both the LC (Fig. $2 O ; t=2.8, p<0.05$ ) and the EC (Fig. $2 S ; t=2.4, p<0.05$ ). Collectively, these findings demonstrate that CSS induces sustained increases in phosphorylated and MC1 tau, including soluble tau oligomers, in two regions with established heightened vulnerability in tauopathies, the LC and EC, and overall effect sizes on AT180, MC1, and Tau soluble oligomers are comparable for LC and EC. 
A

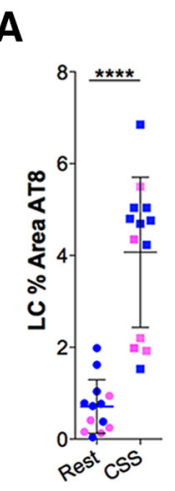

C
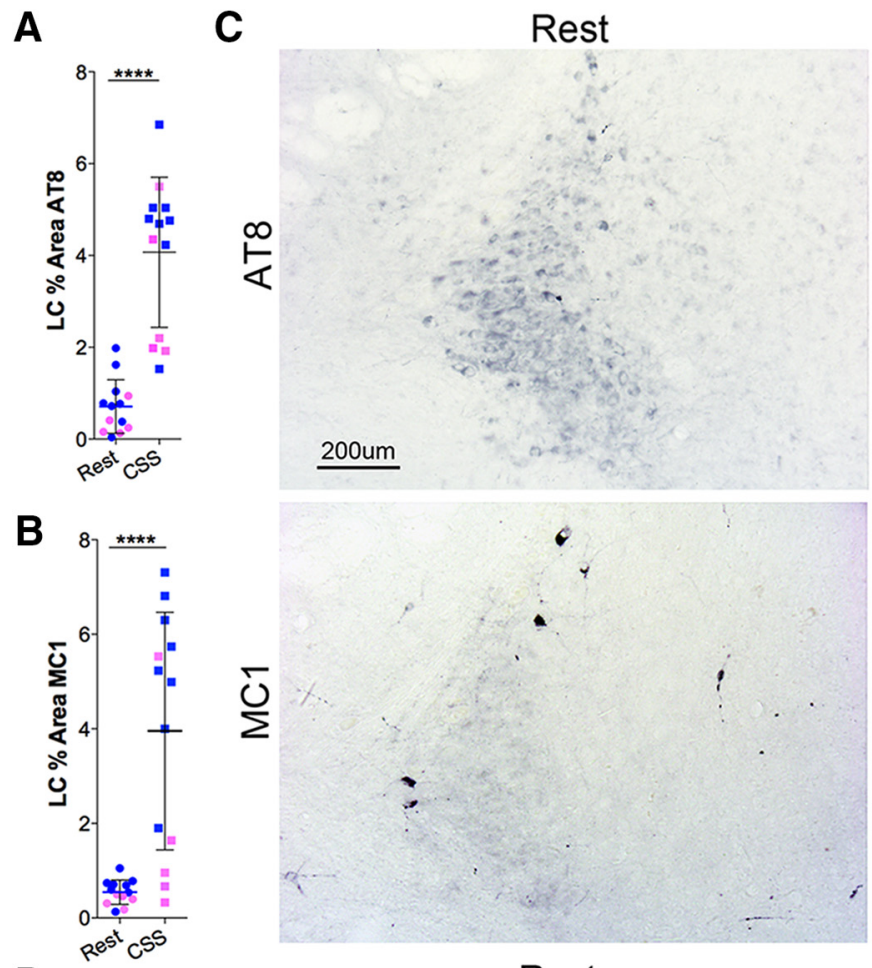

D

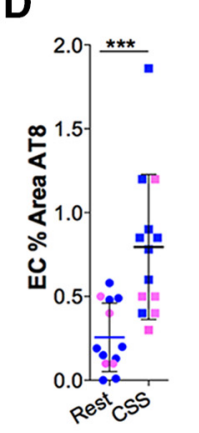

E

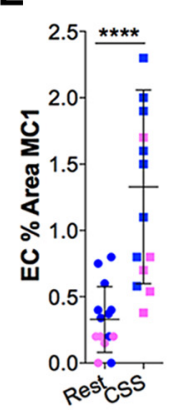

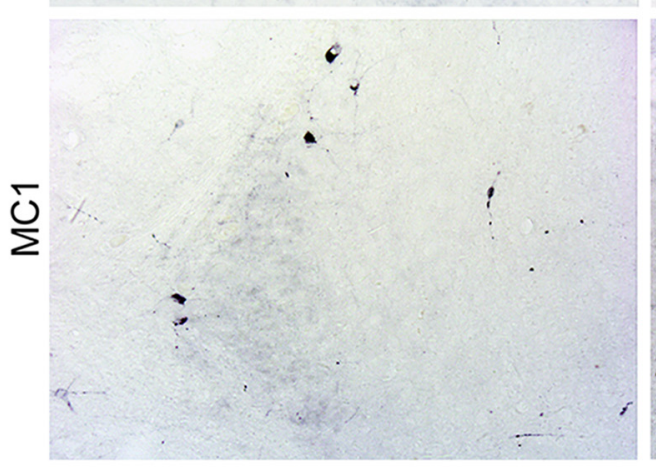

F
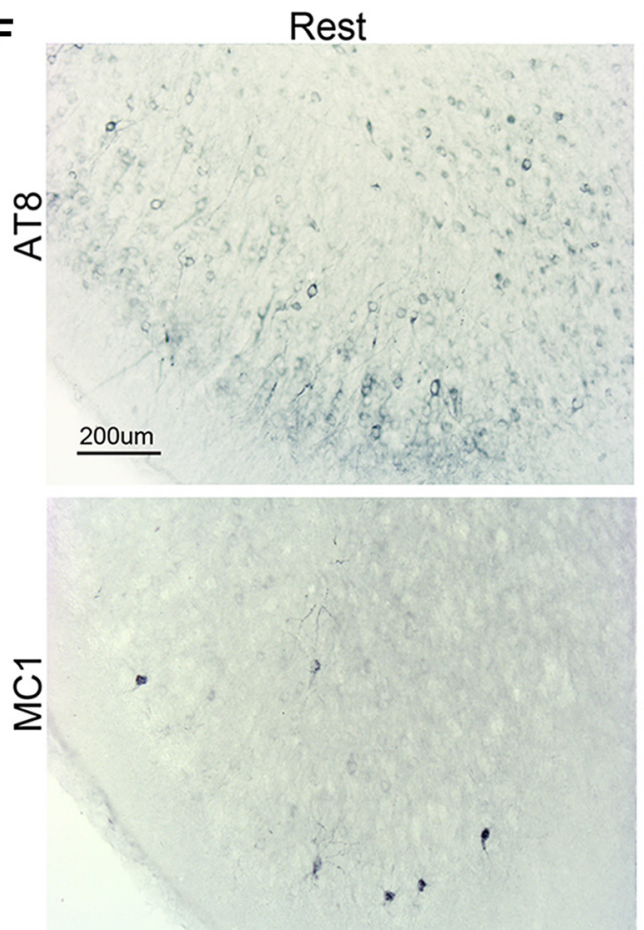

CSS
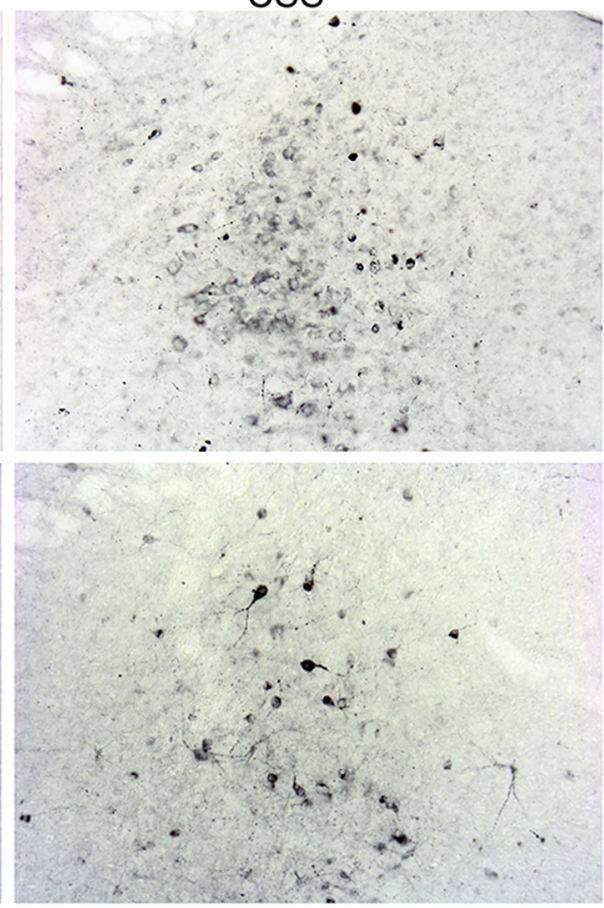

CSS
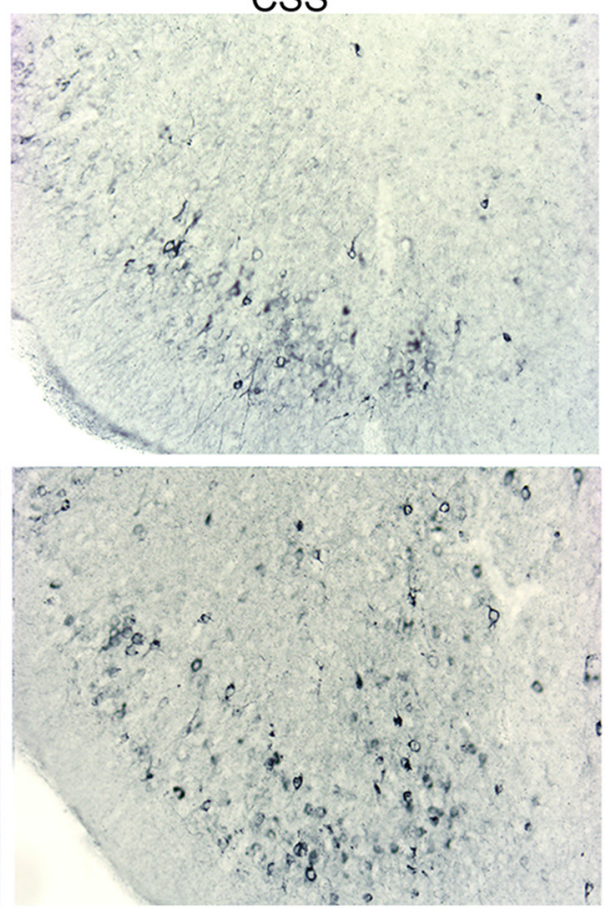

Figure 3. Lasting increases in AT8 and MC1 tau pathology within the LC and EC in response to CSS. A, Individual percentage area with dense AT8 immunoreactivity within LC nucleus in Rest and CSS-exposed mice ( $n=13: 8$ male, 5 female/group). Individual data points: blue represents male; pink represents female. Black lines indicate mean \pm SE. $\boldsymbol{B}$, Individual data points for percentage area with dense MC1-tau labeling within the LC nucleus for Rest and CSS-exposed mice ( $n=13: 8$ male, 5 female/group), labeled as in $A$. C, Representative images of AT8 (top) and MC1 (bottom) immunoreactivity labeled alkaline phosphatase (AP; navy blue) in $60 \mu \mathrm{m}$ coronal sections from the LC from male mice exposed to Rest (left) and CSS conditions (right). $\boldsymbol{D}, \boldsymbol{E}$, Individual percentage area of AT8 $(\boldsymbol{D})$ and MC1 (E) labeling in the EC in Rest and CSS-exposed mice $(n=8$ male, 5 female/group). Data points are color-coded for sex as above. Error bars indicate mean \pm SE. $\boldsymbol{F}$, Images in male mice for EC AT8 (top) and MC1 (bottom) panels in Rest (left) and CSS (right) mice. Data were analyzed with unpaired $t$ tests. ${ }^{* * *} p<0.001$, ${ }^{* * * *} p<0.0001$. Scale bar, 200 $\mu \mathrm{m}$.

\section{Sustained increase in tau pathology following CSS}

To determine whether CSS influences neuronal tau, we examined AT8 (PSer202 andPThr205 tau) and MC1 tau immunohistochemistry within the LC and several forebrain regions particularly sensitive to tau pathology: the EC, basolateral amygdala, and HC (Braak et al., 2011). To relate to soluble tau effects of CSS, mice were examined 6 months after the completion of CSS to identify lasting effects in $n=13$ with 8 male and 5 female/group. P301S mice exposed to CSS had markedly greater AT8 within LCn than Rest P301S mice (Fig. $3 A ; t=7.0, p<0.0001$ ). A similar response was observed for $\mathrm{MC} 1$ immunoreactivity in the LC in response to CSS (Fig. 3B; $t=4.9, p<0.0001$ ). Representative 
images in male mice are shown in Figure 3C. A similar response pattern was observed with increased AT8 in the EC, relative to Rest mice $(t=4.1, p<0.001)$, and MC1 was increased in CSSexposed P301S mice $(t=4.8, p<0.0001)$. Thus, consistent with soluble tau findings, CSS results in sustained hyperphosphorylated tau and MC1 pathology in both the LC and EC.

Findings were next extended to the BLA/LA and HC in the same groups of mice. CSS resulted in an increase in AT8 percent area within the amygdala (Fig. $4 A ; t=3.4, p<0.01$ ) and in the $\mathrm{HC}$ (Fig. $4 D ; t=3.1, p<0.01$ ). Examples of the tau immunohistochemistry are shown in Figure $4 C, F$. CSS also resulted in a sustained increase in $\mathrm{MC} 1$ in the amygdala (Fig. $4 B ; t=4.5, p<$ 0.001 ) and the HC (Fig. $4 E ; t=7.1, p<0.0001$ ). To gain insight into whether CSS influences the formation of NFTs, we next examined Gallyas silver staining within the LC and BLA/LA (amygdala) regions ( $n=6: 3$ male, 3 female/group). Despite the robust increase in AT8 and MC1 within LCn somata, only rare LCn were labeled with silver, and there was no effect of CSS on LCn Gallyas impregnation NFT-like inclusions ( $t=0.0$, not significant; Fig. $5 A, B, E)$. In contrast, CSS significantly increased NFT-like inclusions in amygdala $(t=4.3, p<0.01$; Fig. $5 C-E)$. Thus, CSS effects on AT8/MC1 tau immunoreactivity do not predict silver impregnation responses to CSS.

\section{CSS increases neuron loss within the LC and basolateral amygdala in the P301S murine model of tauopathy}

CSS induces degeneration in a subset of LCn in WT mice (Zhu et al., 2016). In light of the above observed effects of CSS on both soluble tau oligomers and tau pathology in the LC in P301S mice, we examined whether the P301S mutation increases susceptibility to CSS LCn degeneration by examining stereological counts in age-matched WT and P301S mutants exposed to CSS or Rest control conditions. Neurons within the confines of the LC nucleus were counted as $\mathrm{TH}^{+}$or $\mathrm{TH}^{-}$and analyzed collectively with $n=8$ ( 5 male, 3 female/group). Consistent with previous reports, CSS induced loss of LCn in WT mice (Zhang et al., 2014; Zhu et al., 2016) (Tukey $q=8.0, p<0.0001$; Fig. 6A). Representative images are presented in Figure 6B. In Rest P301S mice, LCn counts were not significantly different from Rest WT $(q=2.9$, not significant). A large reduction was observed, however, for P301S mice exposed to CSS ( $q=11.0, p<0.0001)$, so that $\mathrm{LCn}$ counts in P301S mice exposed to CSS were $\sim 30 \%$ lower than counts in CSS-exposed WT mice $(q=4.6, p<0.05)$, demonstrating that CSS can further LCn degeneration in P301S mutant tau mice. Unable to obtain reliable (reproducible) counts of the densely packed EC neurons in layers II/III in $60 \mu \mathrm{m}$ tissue sections, we examined the BLA/LA, where neurons were easy to isolate for counting in $60 \mu \mathrm{m}$ sections, and boundaries for the BLA/LA are readily defined by surrounding white matter tracks and distinct neuronal morphologies (Chareyron et al., 2011). Sample sizes were $n=7$ ( 4 male, 3 female/group). There was no genotype effect under Rest conditions on BLA/LA neurons ( $q=$ 3.2, not significant; Fig. $6 C$ ). Representative images of the BLA/LA are shown in Figure $6 D$. CSS resulted in a significant reduction in BLA/LA in WT mice $(q=7.2, p<0.001)$ and in P301S mice $(q=9.9, p<0.0001)$, so that the BLA/LA neuron estimates in P301S mice following CSS were significantly lower than in WT mice after CSS $(q=5.9, p<0.01)$. Overall, neuron loss in both the LC and BLA/LA occurs in response to CSS, with both LCn counts and BLA/LA counts lower in P301S mice exposed to CSS than in WT mice exposed to CSS.

\section{CFS also hastens neurobehavioral decline and tau pathologic changes}

Because the CSS paradigm increases spontaneous exploratory behavior in a novel environment, which could confound effects of sleep disruption, we also explored the effects of CFS on MC1 tau immunohistochemistry and motor performance in $n=11$ mice ( 8 male, 3 female/group). Overall, CFS increased LC and EC $\mathrm{MC1}$, as illustrated in Figure $7 A-C$. Relative to Rest mice, $\mathrm{MC1}$ percent area increased in the LC $(t=3.0, p<0.01$; Fig. $7 B)$ and also in the EC ( $n=11: 8$ male, 3 female/group; Fig. $7 C ; t=3.5$, $p<0.05)$. We then mapped densely labeled MC1 somata across the brain and found that the density of MC1-labeled neurons in CFS exposed mice was greater overall within areas also affected in Rest mice, as summarized in the brain maps of $\mathrm{MC} 1$ neurons (Fig. 7D). With the ledge walk test, there was no progression observed in the Rest $(t=2.4$, not significant), whereas CFSexposed mice from 5 to 7 months deteriorated in performance $(t=3.8, p<0.01)$. There were also differences in ledge walk scores between the Rest and CFS mice, at 5 months $(t=3.3, p<$ $0.01)$ and at 7 months $(t=4.2, p<0.001)$. Similarly, there were CFS effects on hindlimb retractions scores for the mice at 5 months and 7 months $(t=2.7, p<0.05$ and $t=3.6, p<0.01$, respectively) with no progression in mice for Rest $(t=2.2$, not significant), yet a progression in CSFS-exposed mice CSS $(t=$ $3.8, p<0.01)$.

\section{Sleep disruption activates glia within regions of tau pathology in P301S mice}

Astrocytes and/or microglia are implicated in synapse loss, tau propagation, and neurodegeneration in tauopathies (Asai et al., 2015; Hong et al., 2016; Liddelow et al., 2017). As indices of microglial and astrocyte activation, we examined the percentage area coverage for astrocyte-specific (GFAP) and microglialspecific (Iba-1) and CD68 immunoreactivity within the HC, as a representative tau-susceptible region. Having identified increased tau pathology in the HC in both CSS and CSF mice, we examined both forms of sleep disruption here, matching sexes across sleep condition with $n=11$ ( 8 male, 3 female/group). GFAP percentage coverage of CA1 was increased in CFS, relative to Rest $(q=5.3, p<0.001)$ and in CSS relative to Rest $(q=9.6$, $p<0.0001)$. GFAP signal was higher in CSS than in CFS ( $q=4.3$, $p<0.01$, as summarized in Fig. 8B). Overall results were similar for CD68, where CD68 increased in CFS relative to Rest $(q=4.3$, $p<0.01)$ and was further increased in CSS relative to Rest ( $q=$ $10.5, p<0.0001)$, so that CD68 in CSS was higher than in CFS $(q=6.2, p<0.0001)$. There was no significant increase in Iba-1 for CFS relative to Rest ( $q=2.6$, not significant), although there was a large increase in Iba-1 percent area in CSS mice, relative to Rest $(q=10.0, p<0.0001)$ and relative to CFS $(q=7.4, p<$ 0.0001 ). Collectively, the data show that both astrocyte and microglial reactivity is evident in a sustained fashion following early life sleep disruption.

\section{CSS increases MC1 tau in the LC acutely, whereas effects of CSS on cortical tau are evident only over time}

A second set of mice was randomized to CSS or Rest conditions for 4 weeks and then examined for tau and glial responses immediately following CSS within the LC and HC ( $n=5$ males/group). Representative images of $\mathrm{MC} 1$ in the two regions are presented in Figure $9 A-D$. CSS increased MC1 coverage within the LC ( $q=$ $9.8, p<0.0001$ ) without increasing $\mathrm{MC1}$ immunoreactive area in the HC ( $q=1.8$, not significant), as summarized in Figure 9E. Within the same sections, examined as a triple label, CSS resulted 
A

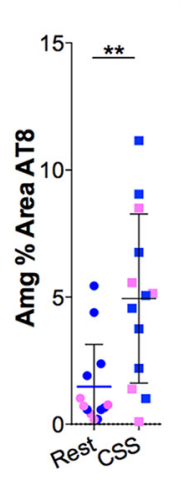

C

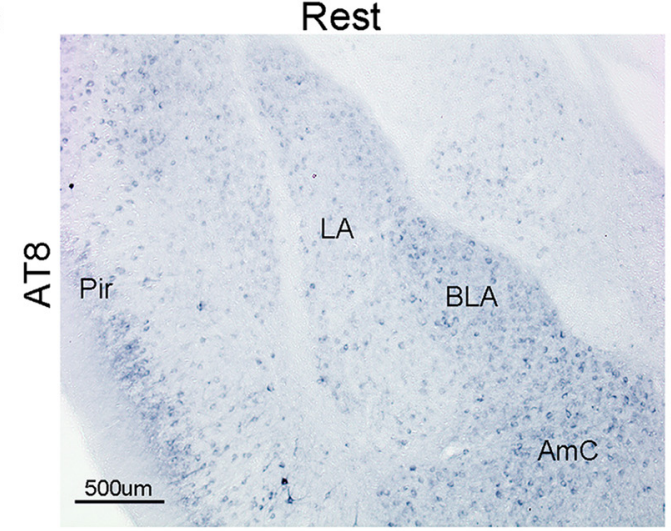

B

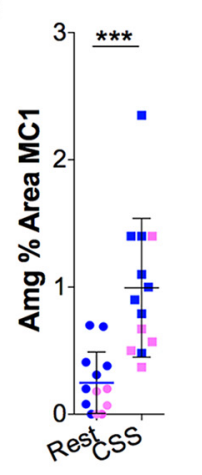

D

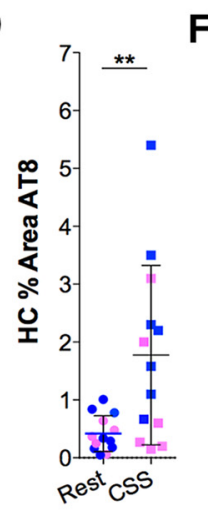

\section{E}

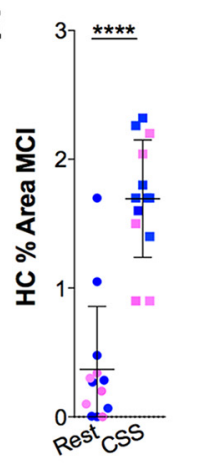

$\bar{\circlearrowright}$

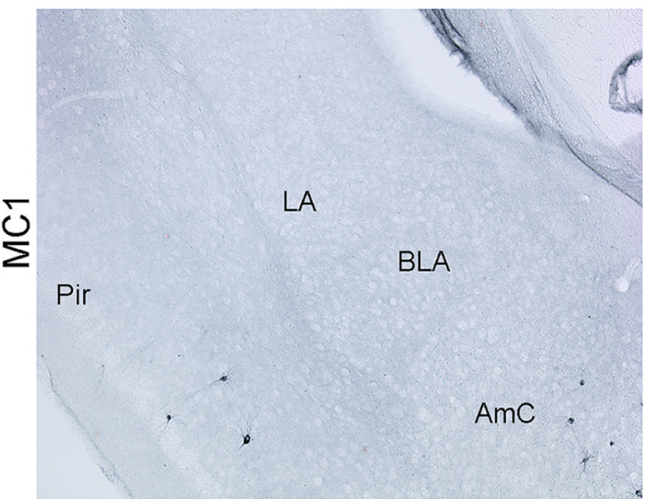

Rest

F
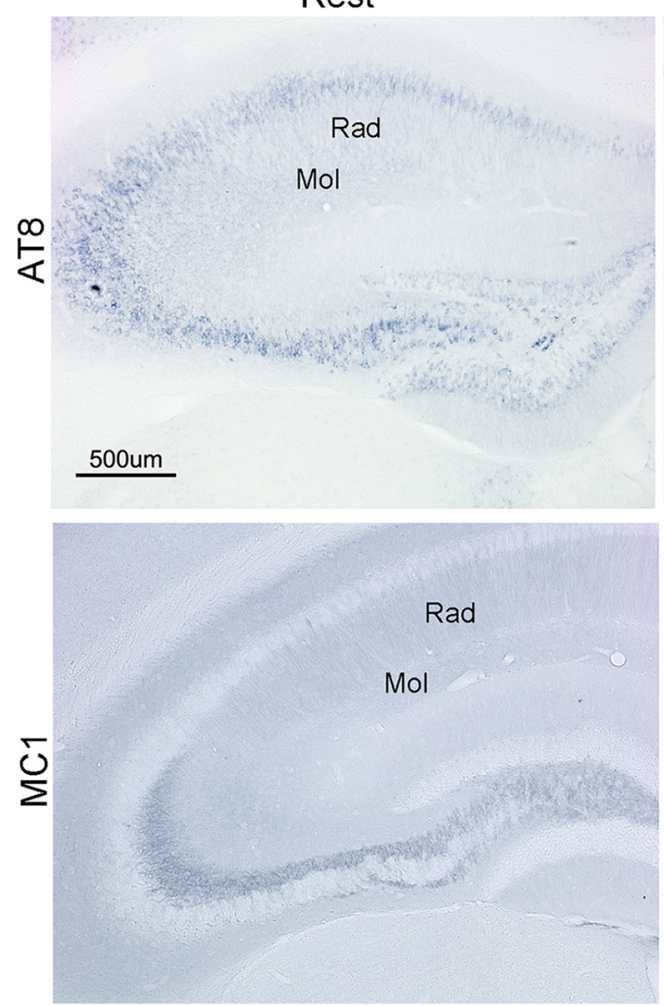

CSS
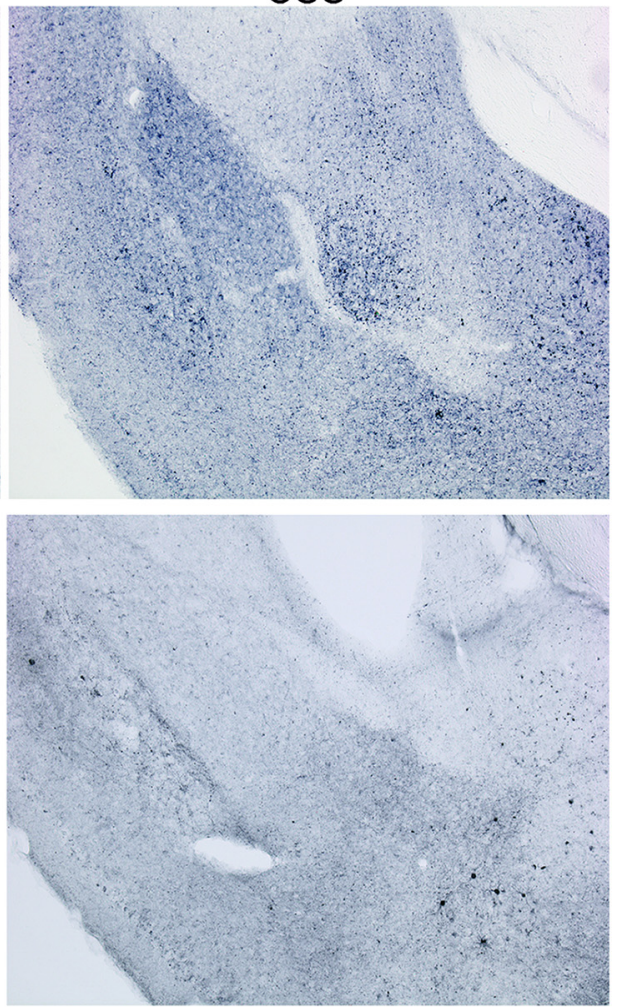

CSS
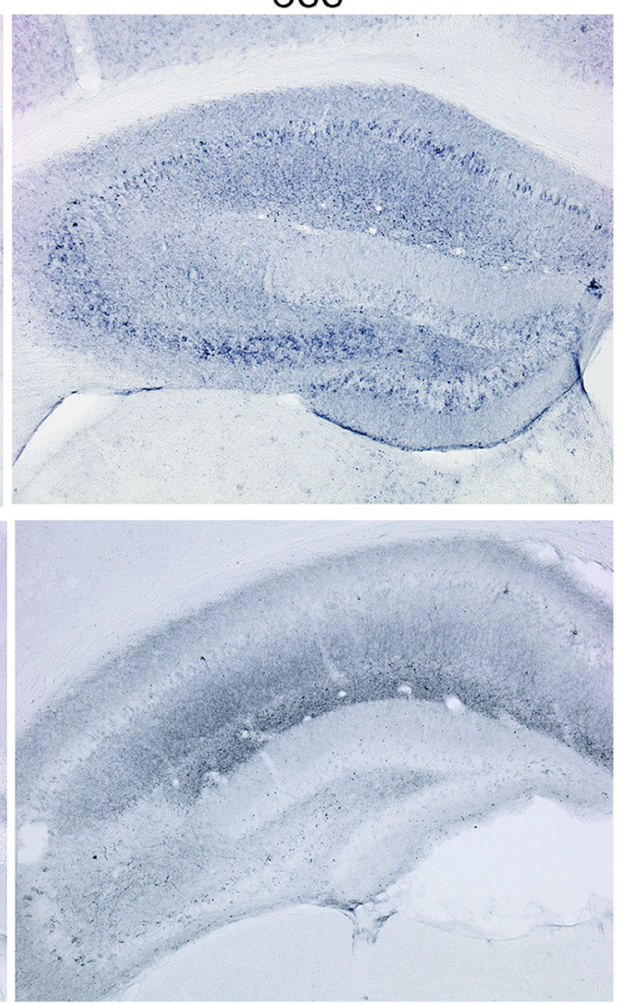

Figure 4. CSS results in sustained tau pathology in BLA/LA (Amg) and HC. $A, B$, Individual data points with $n=13$ ( 8 male, 5 female) for amygdala percentage area with dense AT8 $(A)$ and MC1 (B) labeling. Blue dots represent male; pink dots represent female. Black lines indicate group mean \pm SE, analyzed with unpaired $t$ tests. C, Representative images of AT8 (top) and MC1 (bottom) IHC (blue represents AP) at bregma - 1.70 in male Rest (left) and male CSS (right) mice. Regional references are as follows: LA and BLA nuclei within the amygdala, the amygdala cortex (AmC), and piriform cortex (Pir) in Rest mice. $\boldsymbol{D}, \boldsymbol{E}$, Individual data points for HC percentage area with dense AT8 (D) and MC1 (E) labeling. Blue dots represent male; pink dots represent female. $\boldsymbol{F}$, Six months after CSS exposure ( $n=13: 8$ male, 5 female). Black lines indicate group mean \pm SE. C, Representative images of AT8 (top, bregma -1.70 ) and MC1 (bottom, bregma -2.06 ) IHC (blue represents AP) in male Rest (left) and CSS (right) mice. Regional references are radiatum layer (Rad) and lacanosum moleculare (Mol) in the Rest mice. ${ }^{* *} p<0.01,{ }^{* * *} p<0.001,{ }^{* * * *} p<0.0001$. Scale bars: $C, F, 500 \mu \mathrm{m}$. 

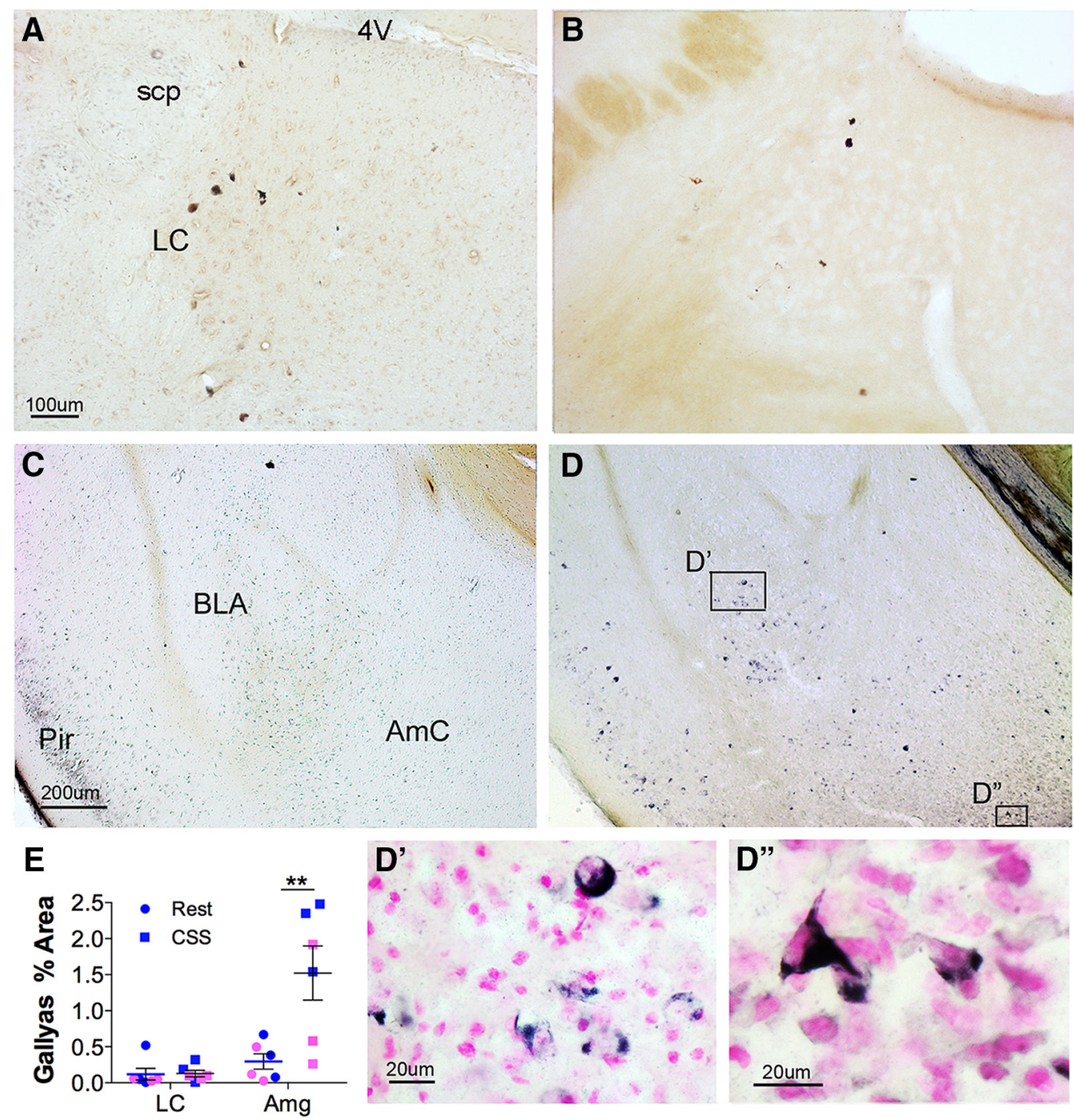

Figure 5. CSS upregulates Gallyas silver labeling. $A, B$, Low-power Gallyas silver impregnation signal in $60 \mu \mathrm{m}$ coronal section of the LC in male Rest control (scp, superior cerebellar peduncle) $(\boldsymbol{A})$ and CSS-exposed mice (B).C, D, Gallyas labeling within the piriform cortx (Pir), LA, and BLA cortex (AmC). D, Section was then counterstained with nuclear fast red for nuclear visualization and reimaged at higher power (for insets $\left.\boldsymbol{D}^{\prime}, \boldsymbol{D}^{\prime \prime}\right)$. $\boldsymbol{E}$, Individual data for percentage area of the $L C$ and $L A / B L A$ (Amg) with silver labeling. $n=6$ ( 3 male, 3 female/group); blue represents male; pink represents female. Black lines indicate mean \pm SE. Data were analyzed with one-way ANOVA and Bonferroni's post hoc analyses. ${ }^{* *} p<0.01$. Scale bars: $\boldsymbol{A}, \boldsymbol{B}, 100 \mu \mathrm{m} ; \boldsymbol{C}, \boldsymbol{D}, 200 \mu \mathrm{m} ; \boldsymbol{D}^{\prime}, \boldsymbol{D}^{\prime \prime}, 20 \mu \mathrm{m}$.

in an immediate increase in GFAP coverage within the LC $(q=$ $9.6, p<0.0001)$ and increased GFAP coverage in the $\mathrm{HC}(q=2.5$, $p<0.05$; Fig. $9 \mathrm{~J})$. Representative images of the GFAP response in the same sections imaged for the MC1 response (Fig. $9 A-D$ ) are presented in Figure $9 F-I$. In summary, P301S mice evidence an early $\mathrm{MC1}$ tau pathology response in the LC, whereas CSS effects in the HC develop only after time, and astrocyte reactivity early on appears more pronounced in the LC than in the HC.

\section{Discussion}

Sleep loss increases brain amyloid- $\beta(\mathrm{A} \beta$ ) levels and $\mathrm{A} \beta$ amyloid plaque in transgenic mouse models of $\mathrm{AD}$ (Kang et al., 2009; Xie et al., 2013). These sleep loss effects on $A \beta$ and amyloid are believed to be exclusively extracellular and limited to the forebrain. In $\mathrm{AD}$, however, tau is implicated in amyloid-induced neural injury (Roberson et al., 2007; Ittner et al., 2010). Yet effects of sleep loss on tau and the progression of tauopathy have been largely unexplored. The present studies examined the effects of chronic sleep disruption on tau protein biochemistry, neuroanatomy, and behavior in a murine model overexpressing human P301S mutant tau. We found that early life CSS advanced the temporal progression of tauopathy, manifesting as a worsening of neurobehavioral impairment and sustained increases in soluble tau oligomers, AT8 and MC1 tau pathology within the LC, HC, EC, and other regions susceptible to tau accumulation, and greater NFT in the amygdala. Moreover, CSS furthered neurodegeneration of LC and amygdala neurons and activated glia in tau-affected regions, with all of these effects evident months after CSS. A second form of sleep disruption, CFS, also advanced neurobehavioral impairment and increased tau pathology. Collectively, the findings identify chronic early life sleep disruption as an important modifier of P301S tauopathy and demonstrate that chronic sleep disruption also has important effects on intraneuronal tau protein processing, in addition to the previously described sleep loss effects on extracellular $\mathrm{A} \beta$ and amyloid.

How would early life sleep disruption induce sustained advancement of tauopathy? We propose several possible mechanisms that may act independently or synergistically to advance the progression of tauopathy. Both paradigms of sleep disruption can result in loss of sirtuin Type 1 (SirT1) in select neurons, including LCn (Zhu et al., 2015, 2016). Deficiency of SirT1 was 
A

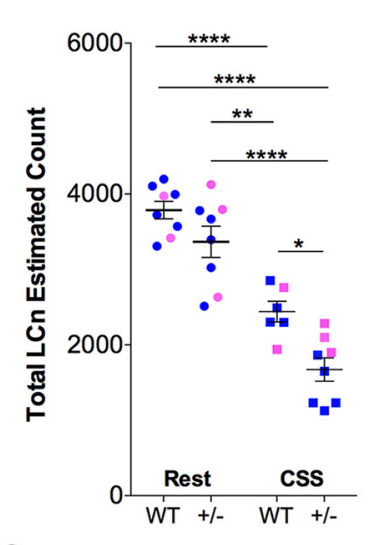

C

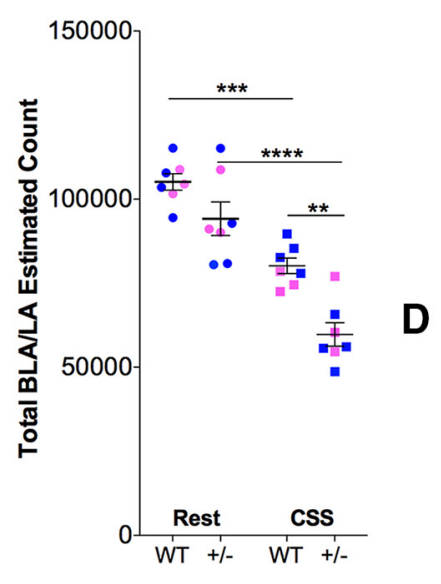

B
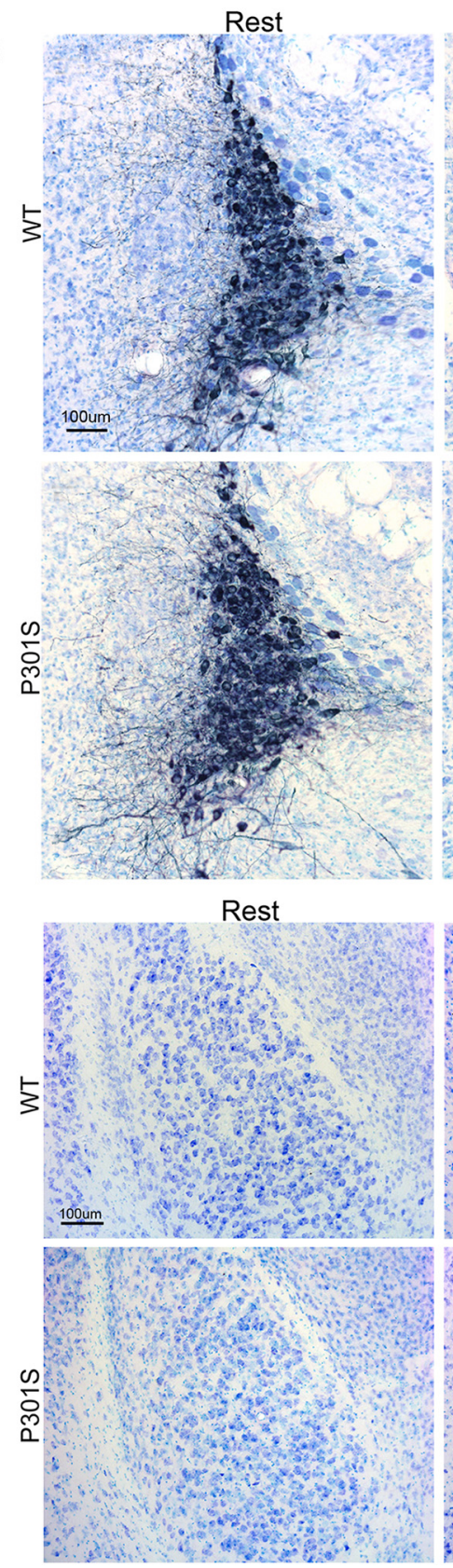
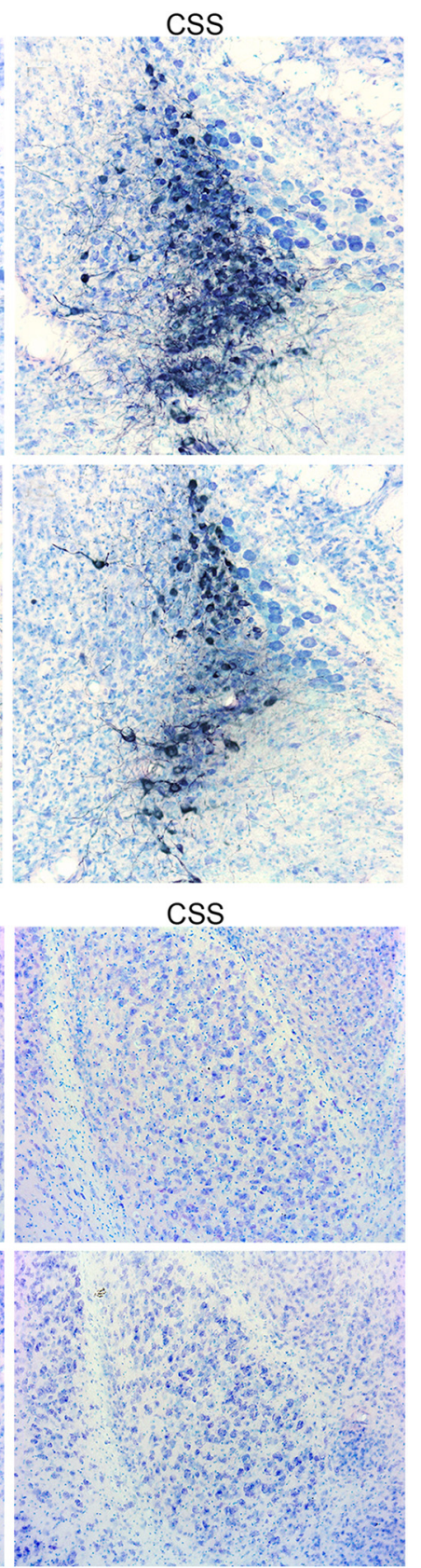

Figure 6. P3015 mice show heightened susceptibility to CSS loss of LC and BL/LA neurons. $A$, Individual $L C$ cell counts ( $n=8: 5$ male, 3 female/group) for unbiased optical fractionator estimates of total LCn in WT and P301S mice in response to Rest control conditions or CSS, followed by 6 months of recovery. Individual data: blue represents male; pink represents female. Black lines indicate mean \pm SE. $\boldsymbol{B}$, Representative $60 \mu \mathrm{m}$ coronal images of $\mathrm{LC}$ in male mice with $\mathrm{TH}^{+}$immunoreactive neurons labeled (navy blue represents AP) and Giemsa stain (lighter blues) to highlight cells/nuclei. , Individual BLA/LA counts (blue represents male; pink represents female; $n=8: 5$ male, 3 female/group) for stereological estimates. Black lines indicate mean \pm SE. $D$, Giemsa-labeled sections showing the BLA with boundaries delineated by external capsule fiber tracts. Data were analyzed with two-way ANOVA and Sidak's posthoc analyses. ${ }^{*} p<0.05$, ${ }^{* *} p<0.01$, ${ }^{* * *} p<0.001$, ${ }^{* * * *} p<0.00001$. Scale bars: $\boldsymbol{B}, \boldsymbol{D}, 100 \mu \mathrm{m}$.

recently shown to worsen neurobehavioral impairments in P301S mice (Min et al., 2018). Thus, a lasting reduction in SirT1 may contribute to the persistent pathologic tau in the present study. Additionally, CSS induced immediate and sustained misfolding of tau, as evidenced by increased MC1 tau pathology within the LC and increased soluble phosphorylated and misfolded (MC1) tau in the EC. The LC is implicated as an early site for misfolded tau in tauopathy and a site from which pathologic tau can propagate (Braak et al., 2011; Iba et al., 2015). There is, however, a recent report suggesting that the EC, but not the LC, is involved early in tau seeding (Kaufman et al., 2018). As CSS increased EC tau in the present study, it is also possible that sleep loss increases tau seeding directly from the EC. In addition, CSS induced significant degeneration of LCn, particularly in P301S mutants, and lesioning of the LC can have lasting effects on the progression of tauopathy. Specifically, early life lesioning of LC neurons (at the same age of our CSS exposure) in P301S mice results in more profound neurobehavioral deficits, in particular memory, and increased gliosis, without increasing tauopathy (Chalermpalanupap et al., 2018). Consistent with this finding, we observed increased impairment in memory and a striking gliosis in response to CSS. Interestingly, LC lesioning does not appear to 
A

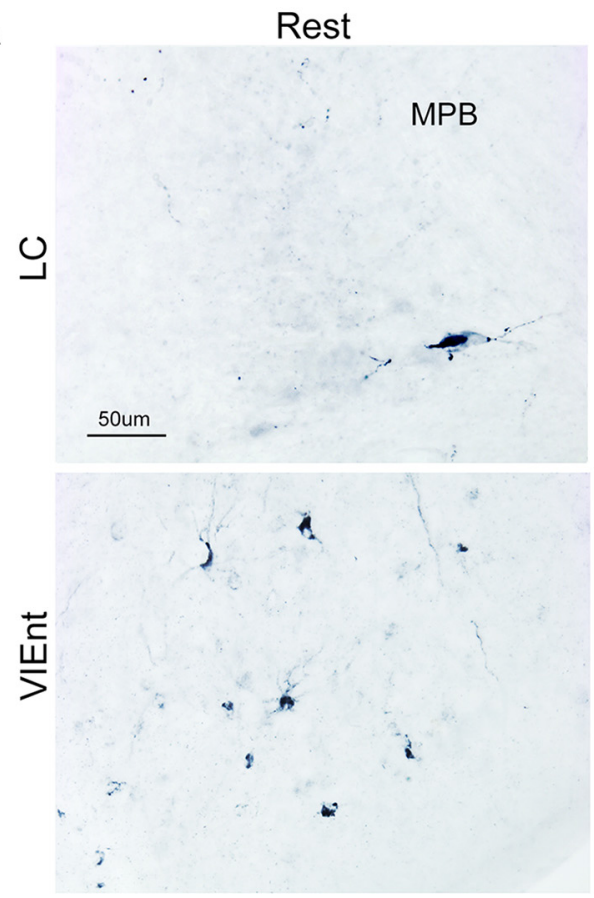

CFS

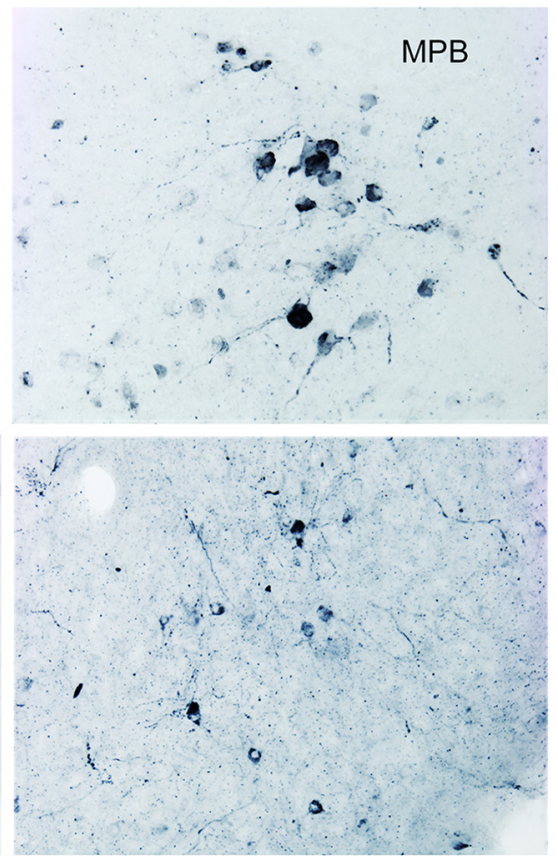

B

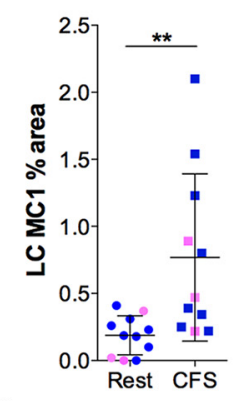

C

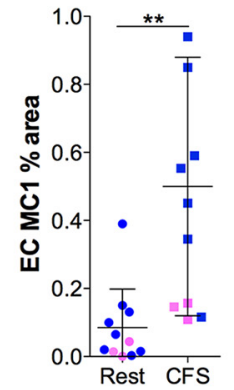

D
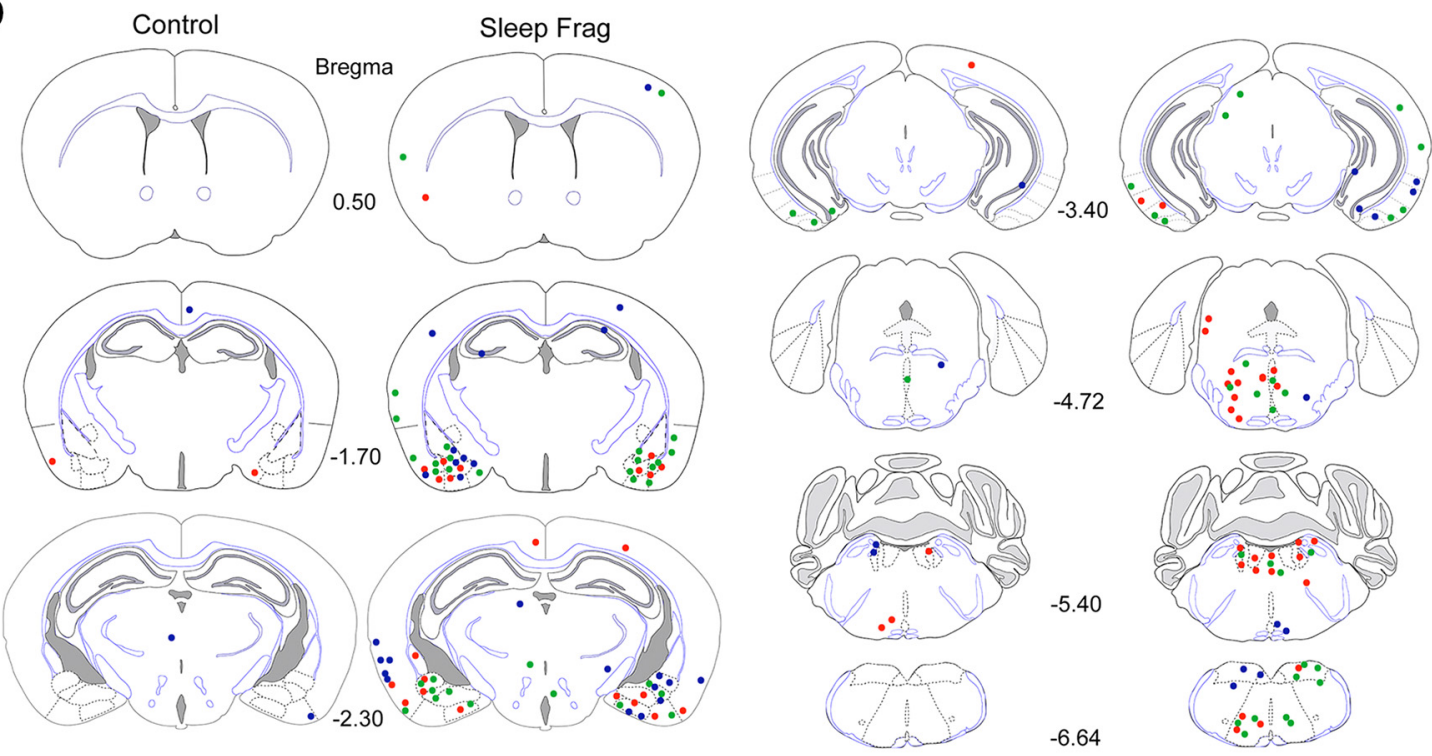

E
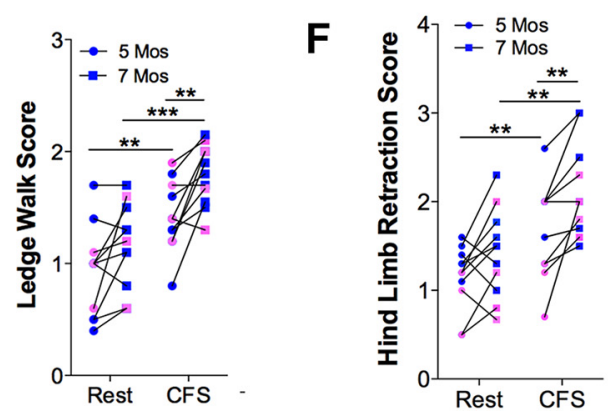

Figure 7. CFS increases MC1 tau pathology in susceptible regions and worsens motor performance. $A$, Representative images of MC1 labeling in LC (top) and ventrolateral EC (VIEnt, bottom). Medial parabrachialis nucleus (MPB) is highlighted to the right of the $L C$ nucleus. $B, C$, Individual MC1 percent area (blue represents male; pink represents female) for $L C$ nucleus $(\boldsymbol{B})$ and $E C(\boldsymbol{C})$ with dense immunoreactivity (blue represents AP; navy represents Rest; $n=11: 8$ male and 3 female/group). $\boldsymbol{D}$, Composite brain mapping of MC1 tau densely labeled neurons in 3 mice 6 months after conditions of Rest and CFS, highlighting the three individual responses as red, green, or blue dots marking labeling sites. $\boldsymbol{E}, \boldsymbol{F}$, Group scores (Rest; $n=11: 8$ male, 3 female) for ledge walk (E) and hindlimb retraction for ages 5 months (closed circles) and 7 months (closed squares). Data were analyzed with two-way ANOVA and Sidak's posthoc analyses. ${ }^{*} p<0.05,{ }^{* *} p<0.01$, ${ }^{* * *} p<0.001$. Scale bar, $50 \mu \mathrm{m}$. 
A
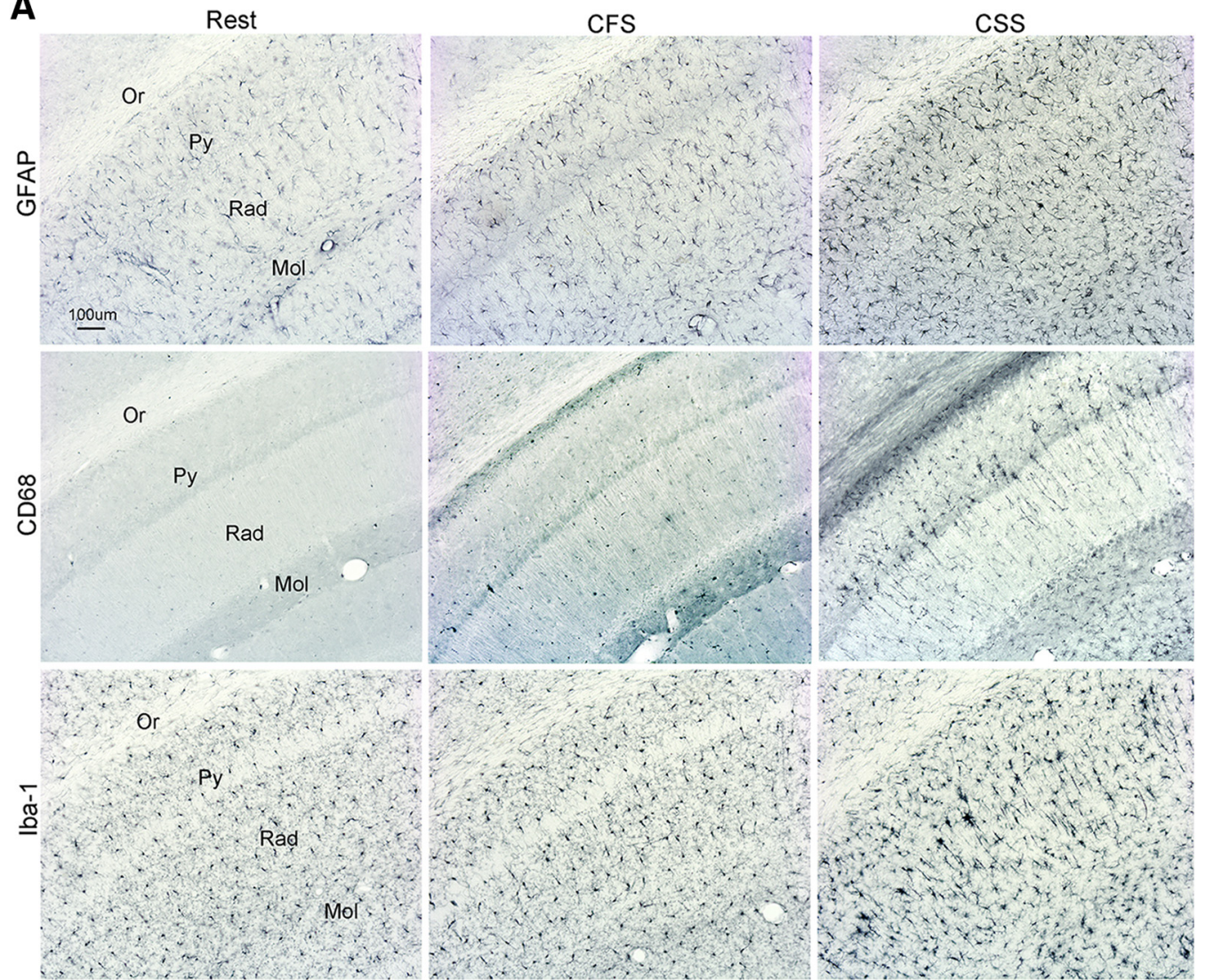

\section{B}

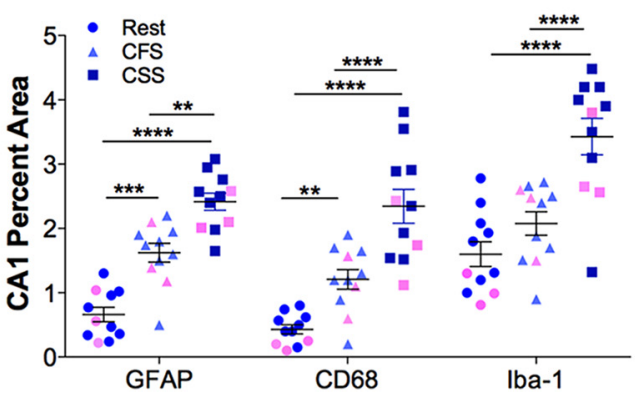

Figure 8. Persistent glial activation in response to chronic sleep disruption in both CSS and CFS. $A$, Representative images of GFAP, CD68, and Iba-1 immunoreactivity (AP blue) in HC lateral CA1 at bregma -2.18 , across conditions in male mice, Rest (left panels), CFS (middle panels), and CSS (right panels). $\boldsymbol{B}$, Percentage area coverage data are presented. Individual responses: blue represents male; pink represents female. Error bars indicate mean \pm SEM. $n=11$ ( 8 male, 3 female) for each sleep condition. Data were analyzed with two-way ANOVA and Sidak's posthoc analyses. ${ }^{* *} p<0.01,{ }^{* * *} p<0.001,{ }^{* * * *} p<0.00001$. Scale bar: $A, 100 \mu \mathrm{m}$.

influence tau pathology, whereas early life sleep disruption does. This may have to do with differences in antibodies used to assess tau pathology, where the only tau species examined after LC lesioning was phosphorylated tau at Ser 306 and 404 (Chalermpalanupap et al., 2018). Alternatively, the composite findings we observe with CSS may include LCn injury and may also include the metabolic resetting as mentioned above. Finally, we note a persistent microglial activation in tau-affected regions. Microglial activation in murine tauopathy can worsen tau spreading and pathology (Maphis et al., 2015). In summary, any one or more of these possibilities may contribute to the persistent progression of tauopathy after CSS and CFS.

CSS increased levels of specific post-translational modifications of tau in P301S mice, which are known to influence the severity of tauopathy in murine models and in humans. Specifically, CSS increased tau phosphorylated at threonine 231 (P231) and $\mathrm{MC} 1$ tau in both the LC and EC. In AD, increased P231 tau levels in the CSF predict lower hippocampal volumes and greater declines in volume over time (Hampel et al., 2005), and P231 tau levels predict cognitive decline in individuals with mild cognitive impairment (Buerger et al., 2002). P231 tau disrupts tubulin intermolecular binding in axons, which may contribute to neuronal injury and demise (Moszczynski et al., 2015; Schwalbe et al., 2015). Additionally, P231 tau is critical for the formation of tau fibrils (Moszczynski et al., 2015). Increases in MC1 tau were also evident following CSS. MC1 antibody detects a pathological conformational change in tau protein, one that is identified early on in $\mathrm{AD}$ and is not detected in normal brains (Weaver et al., 2000). Importantly, its presence also positively correlates with the severity and progression of AD (Mead et al., 2016). Remarkably, CSS resulted in sustained increases in pathogenic tau oligomers, evident at least 6 months after cessation of CSS. This suggests that 
Rest
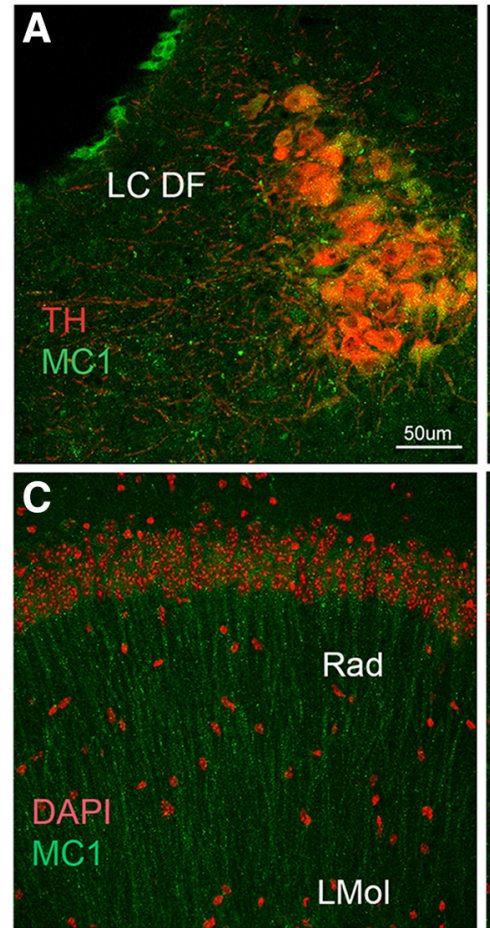

Rest
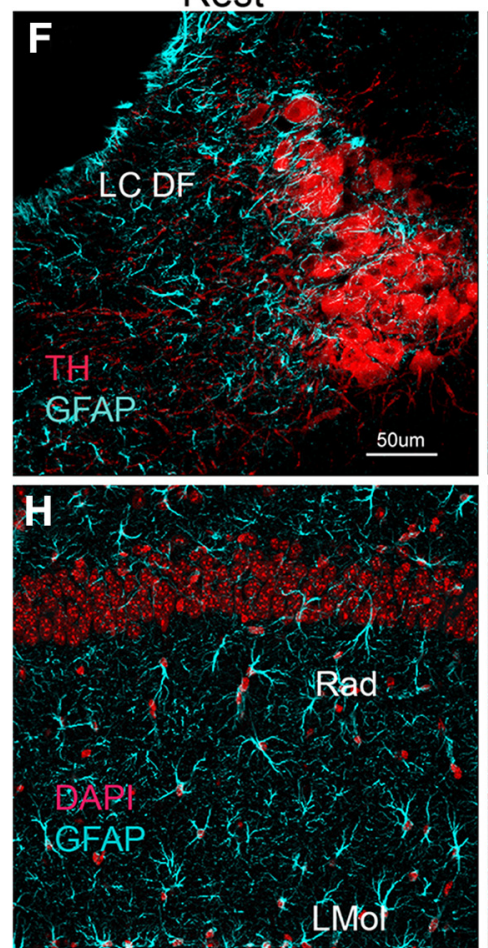

CSS no Recov

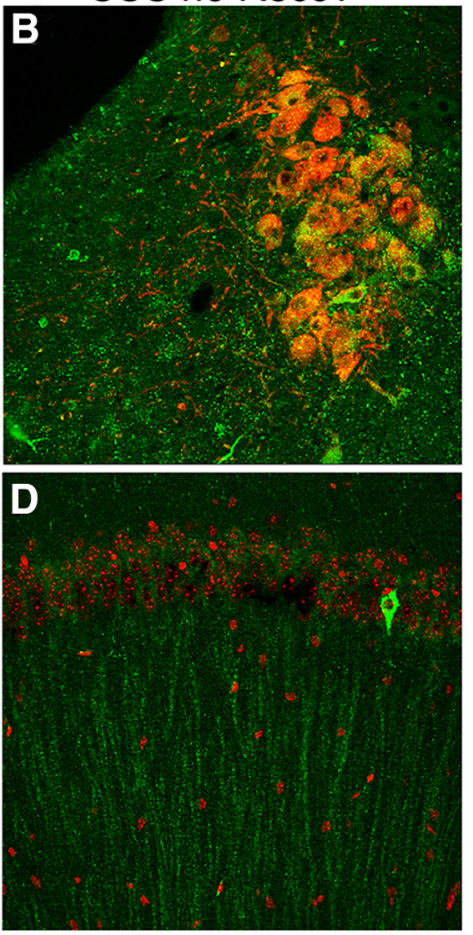

CSS no Recov
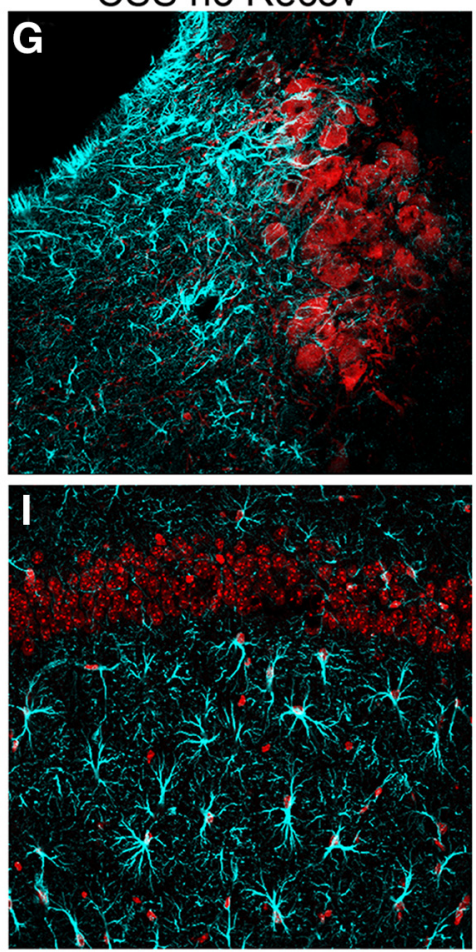

\section{$\mathbf{E}$}

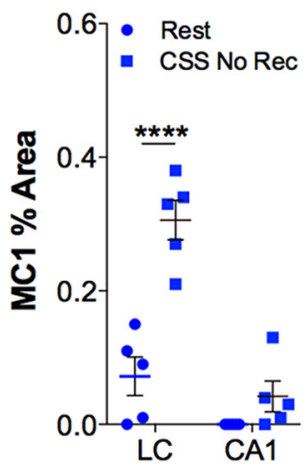

$\mathbf{J}$

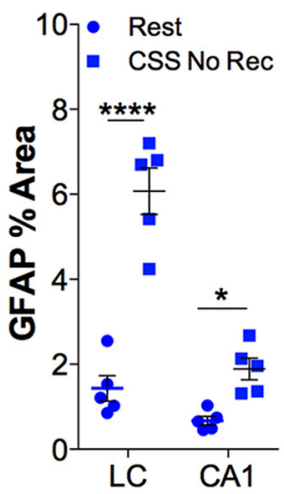

Figure 9. Immediate response to CSS in P3015 mice varies for $\mathrm{LC}$ and HC. $\boldsymbol{A}, \boldsymbol{B}$, Confocal images of MC1 (green) with TH-labeled (red) $\mathrm{LCn}$ in Rest-exposed ( $\boldsymbol{A}$ ) and CSS-exposed (B) mice immediately after exposures. Regional reference, LC dendritic field (LCDF). C, D, Confocal images of MC1 (green) in CA1 HC with DAPI labeling (red) of nuclei to highlight pyramidal neurons. Reference areas are radiatum layer (Rad) and lacanosum moleculare (Mol). $\boldsymbol{E}$, Individual MC1 percent area (with black lines indicating mean \pm SE) in the LC and CA1 region of HC. $\boldsymbol{F}, \boldsymbol{G}$, Confocal images of GFAP (blue) with TH-labeled (red) LCn from the same sections (tripled labeled) shown in $\boldsymbol{A}$ and $\boldsymbol{B}$, revealing a striking GFAP increase over LC DF in response to CSS. $\boldsymbol{H}, \boldsymbol{I}$, Confocal images of GFAP (blue) in CA1 HC with DAPI labeling (red) of nuclei from the same sections imaged for MC1 and DAPI in C and $\boldsymbol{D}$. J, Individual GFAP percentage area (with mean \pm SE) in LC and CA1. ${ }^{*} p<0.05$, ${ }^{* * * *} p<$ 0.0001. Scale bars: $A-D, F-I, 50 \mu \mathrm{m}$.

early life CSS imparts a lasting metabolic resetting in affected neurons, in at least the two regions assayed: the LC and EC. That the same lysate run under nonreducing conditions evidenced oligomeric bands and when processed under reducing conditions revealed a monomeric band supports reversible oxidative tau oligomerization. Disulfide cross-linked tau dimers can aggregate and propagate and are implicated in tauopathy progression (Kim et al., 2015). Thus, CSS results in important tau modifications 
that are implicated in cognitive decline and neural injury in $\mathrm{AD}$, where one of the CSS-induced tau modifications is reversible oxidative oligomerization.

P301S mice showed heightened vulnerability to CSS-induced neurodegeneration in both regions examined: the LC and BLA/ LA. In the LC in P301S mice, CSS neuron loss does not appear to require NFT as the LC in CSS-exposed mice exhibited rare tangles. LCn loss was associated with an increase in LC-soluble tau oligomers and glial activation. Our findings are in keeping with the previously described temporal progression of tauopathy in P301S mice, where neurofibrillary formations occur well after synaptic loss and gliosis (Yoshiyama et al., 2007). There is recent in vivo evidence that oligomers, rather than NFT, parallel neuron loss in tauopathy. Specifically, reducing RNA binding protein TIA1 in P301S mice reduces soluble oligomers and in parallel limits neuronal loss, yet this intervention increased NFT (Apicco et al., 2018). A next important step will be to test the role of disulfide oligomerization in CSS-induced neuron loss in both WT and P301S mice.

Both CSS and CFS increased the severity of motor deficits, the density of tau pathology, and the intensity of both astrocyte and microglial activation, supporting the concept that chronic disruption of sleep, rather than repeated exposure to a novel environment and/or increased ambulation as in CSS, advances tauopathy in the P301S mice. We cannot compare magnitudes of responses, as there is no way to equate severity of sleep disruption across the two models. There were, however, relative differences in the overall response patterns that may provide insight into how the type of sleep disruption may influence the phenotype of tauopathy. Interestingly, the motor deficits started sooner following CFS, whereas EC tau pathology and glial activation appeared more pronounced in response to CSS. We propose that, although chronic sleep disruption (both CSS and CFS) can advance tauopathy, there may be unique metabolic responses to the different forms of sleep disruption (with different patterns of wake durations) which influence the behavioral and pathology outcomes in tauopathy, and these unique responses may contribute to heterogeneity of pathology and neurobehavioral signs across individuals with a given tauopathy. Alternatively, differences in severity of sleep disruption may influence response patterns.

Both CFS and CSS resulted in sustained glial activation. CSS increased microglial activation as evidenced by increased CD68 and Iba-1 percent area, whereas CFS increased only CD68 and not Iba-1. While both Iba-1 and CD68 increases are used to characterize microglial activation, in $\mathrm{AD}$, Iba-1 response can be less robust than the CD68 response (Hendrickx et al., 2017). Thus, both forms of sleep disruption activate microglia. Microglial activation is an early sign in tauopathy, including in the P301S mice, where microglial activation precedes tangle formation (Yoshiyama et al., 2007), but this response may also contribute to disease. Specifically, microglia can propagate tau, whereas depletion of microglia can markedly reduce propagation of tau pathology in a mouse model (Asai et al., 2015). Astrocyte activation was more prominent in CSS than in CFS, at least in the HC, where compared. It is of interest that brain regions with increased MC1 deposition were also regions with increased astrocyte activation, suggesting that these two responses are tightly linked across Rest and CSS conditions.

Collectively, the present findings demonstrate that chronic sleep disruption in early adult life advances the temporal progression of tauopathy. Insufficient sleep in adolescents is increasingly common in modern societies (Keyes et al., 2015). CFS is observed in all cases of obstructive sleep apnea, a disorder with increasing prevalence in adolescents and young adults (Peppard et al., 2013; Güngör, 2014). The above findings suggest that these common forms of chronic sleep disruption may prove to be important and modifiable factors in the progression of tauopathies, including $\mathrm{AD}$.

\section{References}

Apicco DJ, Ash PE, Maziuk B, LeBlang C, Medalla M, Al Abdullatif A, Ferragud A, Botelho E, Ballance HI, Dhawan U, Boudeau S, Cruz AL, Kashy D, Wong A, Goldberg LR, Yazdani N, Zhang C, Ung CY, Tripodis Y, Kanaan NM, et al. (2018) Reducing the RNA binding protein TIAl protects against tau-mediated neurodegeneration in vivo. Nat Neurosci 21: 72-80. CrossRef Medline

Asai H, Ikezu S, Tsunoda S, Medalla M, Luebke J, Haydar T, Wolozin B, Butovsky O, Kügler S, Ikezu T (2015) Depletion of microglia and inhibition of exosome synthesis halt tau propagation. Nat Neurosci 18:15841593. CrossRef Medline

Aston-Jones G, Bloom FE (1981) Activity of norepinephrine-containing locus coeruleus neurons in behaving rats anticipates fluctuations in the sleep-waking cycle. J Neurosci 1:876-886. CrossRef Medline

Aston-Jones G, Rajkowski J, Kubiak P, Alexinsky T (1994) Locus coeruleus neurons in monkey are selectively activated by attended cues in a vigilance task. J Neurosci 14:4467-4480. CrossRef Medline

Bekar LK, Wei HS, Nedergaard M (2012) The locus coeruleusnorepinephrine network optimizes coupling of cerebral blood volume with oxygen demand. J Cereb Blood Flow Metab 32:2135-2145. CrossRef Medline

Braak H, Thal DR, Ghebremedhin E, Del Tredici K (2011) Stages of the pathologic process in Alzheimer disease: age categories from 1 to 100 years. J Neuropathol Exp Neurol 70:960-969. CrossRef Medline

Buerger K, Teipel SJ, Zinkowski R, Blennow K, Arai H, Engel R, HofmannKiefer K, McCulloch C, Ptok U, Heun R, Andreasen N, DeBernardis J, Kerkman D, Moeller H, Davies P, Hampel H (2002) CSF tau protein phosphorylated at threonine 231 correlates with cognitive decline in MCI subjects. Neurology 59:627-629. CrossRef Medline

Chalermpalanupap T, Schroeder JP, Rorabaugh JM, Liles LC, Lah JJ, Levey AI, Weinshenker D (2018) Locus coeruleus ablation exacerbates cognitive deficits, neuropathology, and lethality in P301S tau transgenic mice. J Neurosci 38:74-92. Medline

Chareyron LJ, Banta Lavenex P, Amaral DG, Lavenex P (2011) Stereological analysis of the rat and monkey amygdala. J Comp Neurol 519:3218-3239. CrossRef Medline

Dumont M, Stack C, Elipenahli C, Jainuddin S, Gerges M, Starkova NN, Yang L, Starkov AA, Beal F (2011) Behavioral deficit, oxidative stress, and mitochondrial dysfunction precede tau pathology in P301S transgenic mice. FASEB J 25:4063-4072. CrossRef Medline

Fá M, Puzzo D, Piacentini R, Staniszewski A, Zhang H, Baltrons MA, Li Puma DD, Chatterjee I, Li J, Saeed F, Berman HL, Ripoli C, Gulisano W, Gonzalez J, Tian H, Costa JA, Lopez P, Davidowitz E, Yu WH, Haroutunian V, et al. (2016) Extracellular tau oligomers produce an immediate impairment of LTP and memory. Sci Rep 6:19393. CrossRef Medline

Foote SL, Bloom FE, Aston-Jones G (1983) Nucleus locus ceruleus: new evidence of anatomical and physiological specificity. Physiol Rev 63:844914. CrossRef Medline

Franklin K, Paxinos G (2008) The mouse brain in stereotaxic coordinates, Ed 3. San Diego: Academic.

Gompf HS, Mathai C, Fuller PM, Wood DA, Pedersen NP, Saper CB, Lu J (2010) Locus ceruleus and anterior cingulate cortex sustain wakefulness in a novel environment. J Neurosci 30:14543-14551. CrossRef Medline

Güngör NK (2014) Overweight and obesity in children and adolescents. J Clin Res Pediatr Endocrinol 6:129-143. CrossRef Medline

Guyenet SJ, Furrer SA, Damian VM, Baughan TD, La Spada AR, Garden GA (2010) A simple composite phenotype scoring system for evaluating mouse models of cerebellar ataxia. Journal of visualized experiments: J Vis Exp 39:1787. CrossRef Medline

Hampel H, Bürger K, Pruessner JC, Zinkowski R, DeBernardis J, Kerkman D, Leinsinger G, Evans AC, Davies P, Möller HJ, Teipel SJ (2005) Correlation of cerebrospinal fluid levels of tau protein phosphorylated at threonine 231 with rates of hippocampal atrophy in Alzheimer disease. Arch Neurol 62:770-773. CrossRef Medline 
Hendrickx DA, van Eden CG, Schuurman KG, Hamann J, Huitinga I (2017) Staining of HLA-DR, Iba1 and CD68 in human microglia reveals partially overlapping expression depending on cellular morphology and pathology. J Neuroimmunol 309:12-22. CrossRef Medline

Hong S, Beja-Glasser VF, Nfonoyim BM, Frouin A, Li S, Ramakrishnan S, Merry KM, Shi Q, Rosenthal A, Barres BA, Lemere CA, Selkoe DJ, Stevens B (2016) Complement and microglia mediate early synapse loss in Alzheimer mouse models. Science 352:712-716. CrossRef Medline

Iba M, Guo JL, McBride JD, Zhang B, Trojanowski JQ, Lee VM (2013) Synthetic tau fibrils mediate transmission of neurofibrillary tangles in a transgenic mouse model of Alzheimer's-like tauopathy. J Neurosci 33:10241037. CrossRef Medline

Iba M, McBride JD, Guo JL, Zhang B, Trojanowski JQ, Lee VM (2015) Tau pathology spread in PS19 tau transgenic mice following locus coeruleus (LC) injections of synthetic tau fibrils is determined by the LC's afferent and efferent connections. Acta Neuropathol 130:349-362. CrossRef Medline

Ittner LM, Ke YD, Delerue F, Bi M, Gladbach A, van Eersel J, Wölfing H, Chieng BC, Christie MJ, Napier IA, Eckert A, Staufenbiel M, Hardeman E, Götz J (2010) Dendritic function of tau mediates amyloid-beta toxicity in Alzheimer's disease mouse models. Cell 142:387-397. CrossRef Medline

Kang JE, Lim MM, Bateman RJ, Lee JJ, Smyth LP, Cirrito JR, Fujiki N, Nishino S, Holtzman DM (2009) Amyloid-beta dynamics are regulated by orexin and the sleep-wake cycle. Science 326:1005-1007. CrossRef Medline

Kaufman SK, Del Tredici K, Thomas TL, Braak H, Diamond MI (2018) Tau seeding activity begins in the transentorhinal/entorhinal regions and anticipates phospho-tau pathology in Alzheimer's disease and PART. Acta Neuropathol 136:57-67. CrossRef Medline

Kelly SC, He B, Perez SE, Ginsberg SD, Mufson EJ, Counts SE (2017) Locus coeruleus cellular and molecular pathology during the progression of Alzheimer's disease. Acta Neuropathol Commun 5:8. CrossRef Medline

Keyes KM, Maslowsky J, Hamilton A, Schulenberg J (2015) The great sleep recession: changes in sleep duration among US adolescents, 1991-2012. Pediatrics 135:460-468. CrossRef Medline

Kim D, Lim S, Haque MM, Ryoo N, Hong HS, Rhim H, Lee DE, Chang YT, Lee JS, Cheong E, Kim DJ, Kim YK (2015) Identification of disulfide cross-linked tau dimer responsible for tau propagation. Sci Rep 5:15231. CrossRef Medline

Kuninaka N, Kawaguchi M, Ogawa M, Sato A, Arima K, Murayama S, Saito Y (2015) Simplification of the modified Gallyas method. Neuropathology 35:10-15. CrossRef Medline

Léger L, Goutagny R, Sapin E, Salvert D, Fort P, Luppi PH (2009) Noradrenergic neurons expressing fos during waking and paradoxical sleep deprivation in the rat. J Chem Neuroanat 37:149-157. CrossRef Medline

Liddelow SA, Guttenplan KA, Clarke LE, Bennett FC, Bohlen CJ, Schirmer L, Bennett ML, Münch AE, Chung WS, Peterson TC, Wilton DK, Frouin A, Napier BA, Panicker N, Kumar M, Buckwalter MS, Rowitch DH, Dawson VL, Dawson TM, Stevens B, et al. (2017) Neurotoxic reactive astrocytes are induced by activated microglia. Nature 541:481-487. CrossRef Medline

Lockrow J, Boger H, Gerhardt G, Aston-Jones G, Bachman D, Granholm AC (2011) A noradrenergic lesion exacerbates neurodegeneration in a down syndrome mouse model. J Alzheimers Dis 23:471-489. CrossRef Medline

Maphis N, Xu G, Kokiko-Cochran ON, Jiang S, Cardona A, Ransohoff RM, Lamb BT, Bhaskar K (2015) Reactive microglia drive tau pathology and contribute to the spreading of pathological tau in the brain. Brain 138: 1738-1755. CrossRef Medline

Mead E, Kestoras D, Gibson Y, Hamilton L, Goodson R, Jones S, Eversden S, Davies P, O’Neill M, Hutton M, Szekeres P, Wolak J (2016) Halting of caspase activity protects tau from MC1-conformational change and aggregation. J Alzheimers Dis 54:1521-1538. CrossRef Medline

Min SW, Sohn PD, Li Y, Devidze N, Johnson JR, Krogan NJ, Masliah E, Mok SA, Gestwicki JE, Gan L (2018) SIRT1 deacetylates tau and reduces pathogenic tau spread in a mouse model of tauopathy. J Neurosci 38 : 3680-3688. CrossRef Medline

Moszczynski AJ, Gohar M, Volkening K, Leystra-Lantz C, Strong W, Strong MJ (2015) Thr175-phosphorylated tau induces pathologic fibril forma- tion via GSK3beta-mediated phosphorylation of Thr231 in vitro. Neurobiol Aging 36:1590-1599. CrossRef Medline

Panossian L, Fenik P, Zhu Y, Zhan G, McBurney MW, Veasey S (2011) SIRT1 regulation of wakefulness and senescence-like phenotype in wake neurons. J Neurosci 31:4025-4036. CrossRef Medline

Peppard PE, Young T, Barnet JH, Palta M, Hagen EW, Hla KM (2013) Increased prevalence of sleep-disordered breathing in adults. Am J Epidemiol 177:1006-1014. CrossRef Medline

Przybyla M, Stevens CH, van der Hoven J, Harasta A, Bi M, Ittner A, van Hummel A, Hodges JR, Piguet O, Karl T, Kassiou M, Housley GD, Ke YD, Ittner LM, Eersel J (2016) Disinhibition-like behavior in a P301S mutant tau transgenic mouse model of frontotemporal dementia. Neurosci Lett 631:24-29. CrossRef Medline

Roberson ED, Scearce-Levie K, Palop JJ, Yan F, Cheng IH, Wu T, Gerstein H, Yu GQ, Mucke L (2007) Reducing endogenous tau ameliorates amyloid beta-induced deficits in an Alzheimer's disease mouse model. Science 316:750-754. CrossRef Medline

Sahara N, Lewis J, DeTure M, McGowan E, Dickson DW, Hutton M, Yen SH (2002) Assembly of tau in transgenic animals expressing P301L tau: alteration of phosphorylation and solubility. J Neurochem 83:1498-1508. CrossRef Medline

Santacruz K, Lewis J, Spires T, Paulson J, Kotilinek L, Ingelsson M, Guimaraes A, DeTure M, Ramsden M, McGowan E, Forster C, Yue M, Orne J, Janus C, Mariash A, Kuskowski M, Hyman B, Hutton M, Ashe KH (2005) Tau suppression in a neurodegenerative mouse model improves memory function. Science 309:476-481. CrossRef Medline

Sara SJ (2009) The locus coeruleus and noradrenergic modulation of cognition. Nat Rev Neurosci 10:211-223. CrossRef Medline

Schwalbe M, Kadavath H, Biernat J, Ozenne V, Blackledge M, Mandelkow E, Zweckstetter M (2015) Structural impact of tau phosphorylation at threonine 231. Structure 23:1448-1458. CrossRef Medline

Sinha S, Anderson JP, Barbour R, Basi GS, Caccavello R, Davis D, Doan M, Dovey HF, Frigon N, Hong J, Jacobson-Croak K, Jewett N, Keim P, Knops J, Lieberburg I, Power M, Tan H, Tatsuno G, Tung J, Schenk D, et al. (1999) Purification and cloning of amyloid precursor protein beta-secretase from human brain. Nature 402:537-540. CrossRef Medline

Strange BA, Dolan RJ (2004) Beta-adrenergic modulation of emotional memory-evoked human amygdala and hippocampal responses. Proc Natl Acad Sci U S A 101:11454-11458. CrossRef Medline

Takeuchi H, Iba M, Inoue H, Higuchi M, Takao K, Tsukita K, Karatsu Y, Iwamoto Y, Miyakawa T, Suhara T, Trojanowski JQ, Lee VM, Takahashi R (2011) P301S mutant human tau transgenic mice manifest early symptoms of human tauopathies with dementia and altered sensorimotor gating. PLoS One 6:e21050. CrossRef Medline

Usher M, Cohen JD, Servan-Schreiber D, Rajkowski J, Aston-Jones G (1999) The role of locus coeruleus in the regulation of cognitive performance. Science 283:549-554. CrossRef Medline

Vankov A, Hervé-Minvielle A, Sara SJ (1995) Response to novelty and its rapid habituation in locus coeruleus neurons of the freely exploring rat. Eur J Neurosci 7:1180-1187. CrossRef Medline

Wang Y, Balaji V, Kaniyappan S, Krüger L, Irsen S, Tepper K, Chandupatla R, Maetzler W, Schneider A, Mandelkow E, Mandelkow EM (2017) The release and trans-synaptic transmission of tau via exosomes. Mol Neurodegener 12:5. CrossRef Medline

Weaver CL, Espinoza M, Kress Y, Davies P (2000) Conformational change as one of the earliest alterations of tau in Alzheimer's disease. Neurobiol Aging 21:719-727. CrossRef Medline

West MJ, Gundersen HJ (1990) Unbiased stereological estimation of the number of neurons in the human hippocampus. J Comp Neurol 296:122. CrossRef Medline

Wu JW, Hussaini SA, Bastille IM, Rodriguez GA, Mrejeru A, Rilett K, Sanders DW, Cook C, Fu H, Boonen RA, Herman M, Nahmani E, Emrani S, Figueroa YH, Diamond MI, Clelland CL, Wray S, Duff KE (2016) Neuronal activity enhances tau propagation and tau pathology in vivo. Nat Neurosci 19:1085-1092. CrossRef Medline

Xie L, Kang H, Xu Q, Chen MJ, Liao Y, Thiyagarajan M, O'Donnell J, Christensen DJ, Nicholson C, Iliff JJ, Takano T, Deane R, Nedergaard M (2013) Sleep drives metabolite clearance from the adult brain. Science 342:373-377. CrossRef Medline

Xu H, Rösler TW, Carlsson T, de Andrade A, Bruch J, Höllerhage M, Oertel WH, Höglinger GU (2014) Memory deficits correlate with tau and spine 
pathology in P301S MAPT transgenic mice. Neuropathol Appl Neurobiol 40:833-843. CrossRef Medline

Yamada K, Holth JK, Liao F, Stewart FR, Mahan TE, Jiang H, Cirrito JR, Patel TK, Höchgrafe K, Mandelkow EM, Holtzman DM (2014) Neuronal activity regulates extracellular tau in vivo. J Exp Med 211:387-393. CrossRef Medline

Yoshiyama Y, Higuchi M, Zhang B, Huang SM, Iwata N, Saido TC, Maeda J, Suhara T, Trojanowski JQ, Lee VM (2007) Synapse loss and microglial activation precede tangles in a P301S tauopathy mouse model. Neuron 53:337-351. CrossRef Medline

Youmans KL, Leung S, Zhang J, Maus E, Baysac K, Bu G, Vassar R, Yu C, LaDu MJ (2011) Amyloid-beta42 alters apolipoprotein E solubility in brains of mice with five familial AD mutations. J Neurosci Methods 196: 51-59. CrossRef Medline

Zhang J, Zhu Y, Zhan G, Fenik P, Panossian L, Wang MM, Reid S, Lai D, Davis JG, Baur JA, Veasey S (2014) Extended wakefulness: compromised metabolics in and degeneration of locus ceruleus neurons. J Neurosci 34:4418-4431. CrossRef Medline

Zhu Y, Fenik P, Zhan G, Xin R, Veasey SC (2015) Degeneration in arousal neurons in chronic sleep disruption modeling sleep apnea. Front Neurol 6:109. CrossRef Medline

Zhu Y, Fenik P, Zhan G, Somach R, Xin R, Veasey S (2016) Intermittent short sleep results in lasting sleep wake disturbances and degeneration of locus coeruleus and orexinergic neurons. Sleep 39:1601-1611. CrossRef Medline 